\title{
Slug flow heat transfer without phase change in microchannels: A review
}

\author{
Thilaksiri Bandara $^{a}$, Nam-Trung Nguyen ${ }^{b}$ and Gary Rosengarten ${ }^{a *}$ \\ ${ }^{a}$ School of Aerospace, Mechanical and Manufacturing Engineering, RMIT University, \\ GPO Box 2476, Melbourne, Victoria 3000, Australia \\ ${ }^{b}$ QLD Micro- and Nanotechnology Centre, Nathan Campus, Griffith University, 170 \\ Kessels Road QLD 4111, Australia
}

\begin{abstract}
Two-phase flow without phase change can radically increase the heat transfer rate in microchannels due to the internal recirculation of the fluids. In this paper, both numerical and experimental studies on the hydrodynamics and heat transfer of two-phase flow without phase change in small channels and tubes are reviewed. These two-phase flows are either made up of gas-liquid or immiscible liquid-liquid slug flows. This review includes a general introduction of the hydrodynamics of two-phase flow in microchannels and shows that there is little agreement between measured and predicted pressure drop. Furthermore heat transfer rates are examined in the form of Nusselt number $(\mathrm{Nu})$ correlations based on different flow parameters. Values are compared using a standard flow regimes for two-phase slug flow indicating huge variability (over 500\%) in the $N u$ values obtained from reported correlations. We attribute this to insufficient description and consideration of the flow

\footnotetext{
*Corresponding author. Tel: +61 39925 8020; Fax: +61 399258099

Email address: gary.rosengarten@rmit.edu.au (Thilaksiri Bandara ${ }^{a}$, Nam-Trung Nguyen $^{b}$ and Gary Rosengarten ${ }^{a}$ )
} 
conditions. Finally a perspective on future research directions in the field is suggested, including control through wettability and the use of novel liquids. Keywords: Microchannels, Microfluidics, Slug flow, Taylor flow, Heat transfer, Two-phase flow

\section{Introduction}

The use of microchannels for fluid conduits has significant advantages in a variety of applications. Some of these applications include, heat exchangers, micro-reactors, lab-on-a-chip, micro-electronics, and micro electro mechanical systems (MEMS). In heat exchangers, the amount of heat that can be removed scales as the surface area of the cooling channels, so massively parallel microchannels have the potential to transfer large heat fluxes. Large heat flux removal has become particularly important with the increase in transistor density in microelectronics. For example, traditional air cooling has become ineffective in the latest microelectronic systems due to the reduced equipment size, increased heat flux and increased resistance to air flow by compact packing of components in the systems. Therefore, micro-electronic cooling has gained significant interest over the past few decades. Cooling techniques such as falling film cooling, spray cooling, and heat pipes were introduced. However, these techniques proved not to be as effective as expected to cool chips (Ebadian and Lin (2011)), and other low-cost, efficient heat removal methods may be required.

The concept of heat removal by means of liquid flow in microchannels was first introduced by Tuckerman and Pease for electronic cooling. A heat removal rate of $0.79 \mathrm{~kW} / \mathrm{cm}^{2}$ with single phase flow was demonstrated (Tucker- 
man and Pease (1981); Asthana et al. (2011)). While impressive, single-phase heat transfer is still limited to comparatively low heat fluxes. Computer chips currently require cooling rates up to approximately $1 \mathrm{~kW} / \mathrm{cm}^{2}$ (Bar-Cohen et al. (2006)), meaning new solutions need to be found for the next generation of devices that maximise heat transfer rates with large pressure drops.

The heat transfer rate for boiling flow in microchannels is much higher than that of its single-phase counterpart due to the large heat of vaporization (Asthana et al. (2011); Betz and Attinger (2010)). Mudawar and Bowers (1999) have shown that flow boiling can dissipate heat at a rate of $10 \mathrm{~kW} / \mathrm{cm}^{2}$, which is 10 times higher than that for single phase flow (Asthana et al. (2011); Mudawar and Bowers (1999)). Even though flow boiling has been shown to be effective for electronic cooling, it has the drawback of being difficult to control due to back flow and instabilities in the flow. These instability constraints may be overcome while maintaining hight heat transfer rates by using a separate fluid phase such as gas or an immiscible liquid into a main continuous liquid - so called two phase flow without phase change.

The potential of two-phase flow to provide a high heat transfer rate compared to traditional single phase flow is due to two main reasons; internal recirculation within the liquid slugs which promotes the radial mixing of fluids, leading to a greater radial heat transfer rate, and the higher local fluid velocity in the secondary phase plug leading to a higher heat transfer coefficient (refer to Muzychka et al. (2011a)). Above a critical capillary number there exists a thin liquid film between the channel wall and the secondary phase fluid droplet, which has a significant effect on heat and mass transfer. A detailed explanation of this will be given in section 2.1. This type of flow 
was named as Taylor flow after the pioneering studies of Taylor (1961). Figure 1a illustrates the main properties of Taylor flow including the liquid film between the droplets and the wall. However, these fluid droplets can flow without creating a thin film at low capillary numbers $(C a)$ by sliding along the channel wall ( Figure 1b) due to the weak shear forces which can not overcome the adhesion forces. We call this sliding slug flow/slug flow, while some researchers use slug flow for both two-phase flows with and without a thin liquid film (Walsh et al. (2010); Jovanovic et al. (2011)).

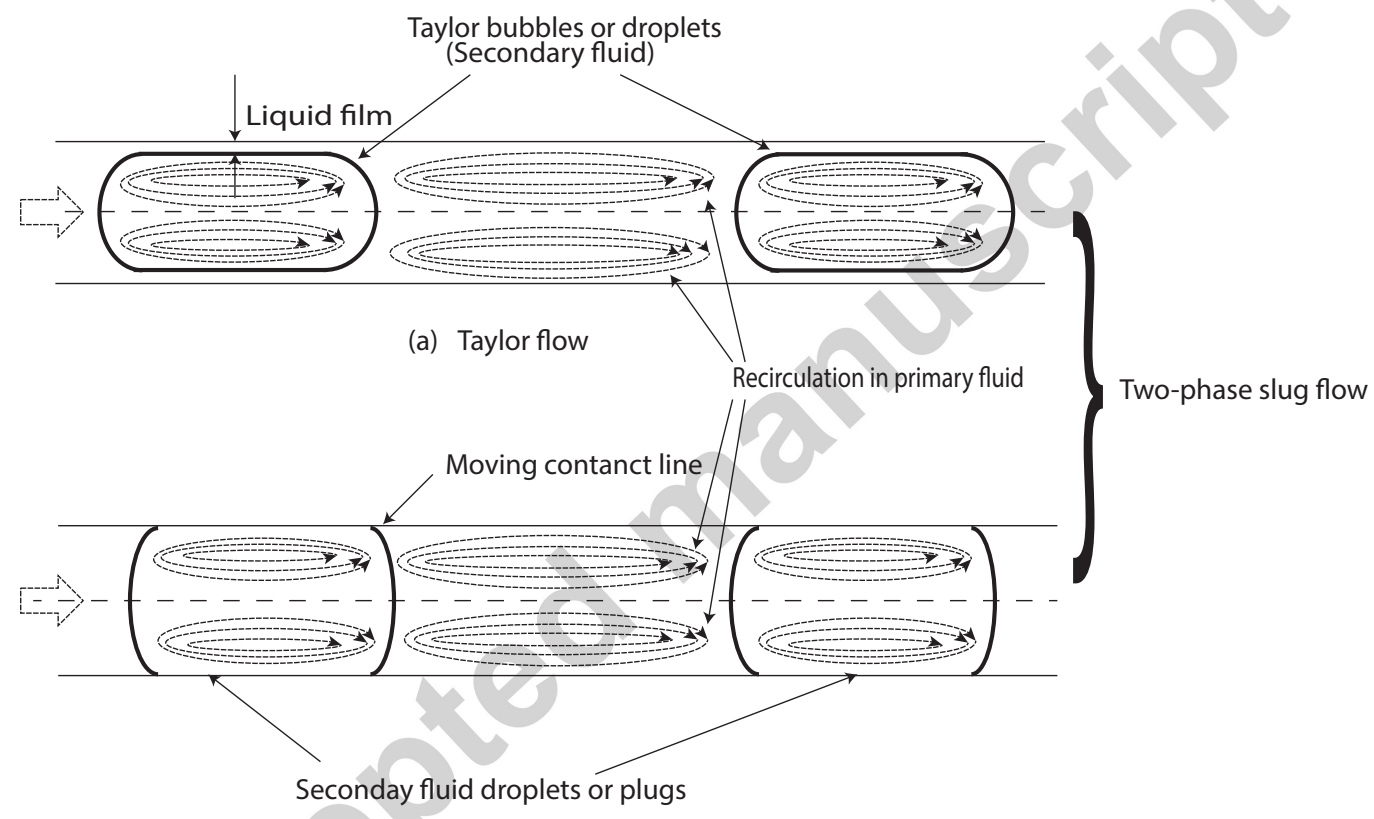

(b) Sliding slug flow

Figure 1: Schematic diagram of a two-phase flow, (a) Taylor flow which has a thin liquid film, (b) sliding slug flow which does not have a liquid film.

Other than slug and Taylor flow, there are various other types of twophase flow patterns such as dispersed bubbly flow, liquid ring flow, and liquid lump flow etc, which have been identified in flow visualization experiments 
(Serizawa et al. (2002); Kreutzer et al. (2005a)). However, slug/Taylor flow is very easy to produce at non-boiling flow conditions, particularly in microchannels where surface tension forces often dominate. Extensive research work has been carried out on two-phase slug flow in microchannels particularly concerning hydrodynamic characteristics such as velocity of bubbles, void fraction, liquid film thickness, pressure loss and mass transfer enhancement (Bretherton (1961); Kreutzer et al. (2005a); Leung et al. (2010); Suo and Griffith (1964); Liu et al. (2005); Abadie et al. (2012)). In fact mass transfer in microreactors can be the limiting factor in reaction rates and Taylor flow has been shown to significantly increase in mass transfer for gasliquid and liquid-liquid two-phase flows compared to single-phase liquid flow of the same carrying fluid (Kashid et al. (2005); Di Miceli Raimondi et al. (2008); Kreutzer et al. (2005a)). It has been shown that the mass transfer increases through the interface and internal diffusion rates increase too as a function of Capillary number.

Although there have been previous reviews on both experimental and numerical studies (Angeli and Gavriilidis (2008); Gupta et al. (2010b); Muzychka et al. (2011b); Talimi et al. (2012)) for two-phase flow and associated heat transfer phenomena, the field has progressed recently, particularly for microscale flows. The aims of the present review paper are: (1) to detail the important two-phase flow parameters and current measurement techniques, (2) to address the challenges and difficulties in the analysis of heat transfer numerically and experimentally in two phase flow, (3) to report recent key findings in the literature on heat transfer in two-phase flow research, and (4) to present research gaps which need to be considered for future research work 
in the area. In this paper we cover numerical and experimental work carried out on the hydrodynamics and heat transfer for non-boiling two-phase segmented flow .

\section{Hydrodynamics of Slug flow}

The earliest studies of non-boiling two-phase flow with slugs of a discontinuous phase in a continuous liquid were reported by Fairbrother and Stubbs (1935), Taylor (1961) and Bretherton (1961). Effects which are not important in macro sized channels become dominant in small channels, such as the surface tension force. Multi-phase flow in microchannels takes different forms, such as suspended droplets, channel-spanning slugs and annular flow based on the relative magnitude of the different forces such as viscous, interfacial, and inertial forces(Gupta et al. (2010b)). In microchannels gravitational forces are almost always negligible and the flow is generally dictated by surface tension and viscosity. This means the three important nondimensional parameters for slug flow in microchannels are Reynolds number, capillary number and Weber number which are given in Table 1 . The symbols, $U, D, \rho, \mu$, and $\sigma$ represent fluid velocity, diameter of channel, density of fluid, dynamic viscosity of fluid and surface tension. These non-dimensional groups define the nature of the flow and heat transfer rates. The heat transfer rate is intrinsically linked to the hydrodynamics, so the important slug flow parameters are discussed next.

\subsection{Film thickness}

Taylor bubbles/droplets may be separated from the channel wall by a thin liquid film of the primary liquid phase as show in Figure 1. Shear 
Table 1: Non-dimensional groups associated with two-phase flow and heat transfer in microchannels

\begin{tabular}{llll}
\hline Name & Notation & Formula & Physical Interpretation \\
\hline Reynolds Number & $R e$ & $\frac{\rho U D}{\mu}$ & $\frac{\text { Inertial force }}{\text { Viscous force }}$ \\
Capillary number & $C a$ & $\frac{\mu U}{\sigma}$ & $\frac{\text { Viscous force }}{\text { Surface tension force }}$ \\
Weber number & $W e$ & $\frac{\rho U^{2} D}{\sigma}$ & $\frac{\text { Inertial force }}{\text { Surface tension force }}$ \\
\hline
\end{tabular}

stress on the bubbles from the liquid film is much smaller than the shear stress on the wall from the liquid film. As a result of this, the bubbles or droplets usually flow with a slightly higher velocity than the continuous fluid velocity. The knowledge of film thickness is important for practical applications that involve heat and mass transfer from the channel wall to the liquid and pressure drop (Kreutzer et al. (2005a); van Baten and Krishna (2004)).

The film thickness can be measured experimentally using direct and indirect methods. In the direct method, the film thickness is measured using high quality images, either free from the optical distortion caused by curved channel walls (Aussillous and Quere (2000)), or corrected for the optical distortion Han and Shikazono (2009b,a). In indirect methods, bubble velocity is measured experimentally and then the film thickness is calculated based on the velocity. This requires knowledge of the velocity profile in the liquid film. Some researchers considered the film as being stagnant such as Suo and Griffith (1964) and Warnier et al. (2007). Suo and Griffith introduced a re- 
lationship between film thickness and flow velocities as shown in equation 1 , where $\delta$ is the film thickness, and $U_{T P}$ and $U_{B}$ are two-phase mixture velocity and bubble velocity respectively.

$$
\frac{\delta}{D}=\frac{1}{2}\left(1-\sqrt{\frac{U_{T P}}{U_{B}}}\right)
$$

Many experimental and numerical studies have been carried out on liquid film thickness in two-phase flow. Bretherton (1961) suggested an analytical expression for the liquid film thickness based on lubrication theory where $R$ is the radius of channel:

$$
\frac{\delta}{R}=1.34 C a^{2 / 3}
$$

Bretherton's expression agreed with the experimentally measured film thickness for a range of capillary numbers from $10^{-3}$ to $10^{-2}$, but the measured film thickness was significantly larger than the theoretical values for $C a$ below $10^{-3}$. Ratulowski and Chang (1990) explained the discrepancy between experimental values and analytical values for low capillary numbers by taking the effect of trace impurities (Marangoni effect) into account.

Irandoust and Andersson (1989) proposed an empirical correlation as shown in equation 3 to predict the film thickness based on their experimental results over a wide range of conditions $\left(9.5 \times 10^{-4}<C a<1.90,0.42<R e<\right.$ 860 , and $1<R e / C a<140,000)$.

$$
\frac{\delta}{D}=0.18\left[1-\exp \left(-3.08 C a^{0.54}\right)\right]
$$

Aussillous and Quere (2000) developed an expression for the film thickness based on scaling arguments and Taylor's experimental data (Taylor (1960)) shown in equation 4 . It was found that the liquid film thickness agreed well 
with Taylor's data for small $C a$ and flow with negligible inertia $(R e<1)$.

$$
\frac{\delta}{D}=\frac{1}{2}\left(\frac{1.34 C a^{2 / 3}}{1+3.35 C a^{2 / 3}}\right)
$$

In reality, inertial effects can have an effect on the film thickness even for low Re. Heil (2001) studied numerically the effect of inertial force on the liquid film thickness for capillary and Reynolds numbers in the ranges $0.05<$ $C a<5$ and $0<R e<280$, and showed that film thickness depends on both Reynolds number and capillary number. This was later verified with experiments Kreutzer et al. (2005b). This indicates that inertia can be significant even when $R e \ll 1$ which agrees with the work of de Ryck (2002) who showed that the ratio of $\mathrm{Re} / \mathrm{Ca}$ plays an important role in the inertia to film thickness relationship but no specific correlation was presented.

Recently Leung et al. (2012a) measured the film thickness over a wide range of capillary and Reynolds numbers $(0.001<C a<0.18$ and $10<$ $R e<1100$ ). Three different liquid phases (Water, Water/Ethylene Glycol, and Ethylene Glycol) were used in their experiments and the film thickness for Ethylene glycol and gas two-phase flow had a good agreement with equation 4. While their results compared favourably to equation (3) for the Water/Ethylene Glycol system there were unexplained discrepancies for the other liquid combinations.

There are other parameters that affect the film thickness. Using a high resolution laser focus displacement meter, the film thickness in a micro tube was measured directly by Han and Shikazono (Han and Shikazono (2009a,b)), indicating that the liquid slug length (Figure 2) has a weak effect on film thickness. However, the bubble length has a considerable effect on the film thickness. Short bubbles with length $L_{b}<2 D$ had a thicker film than longer 


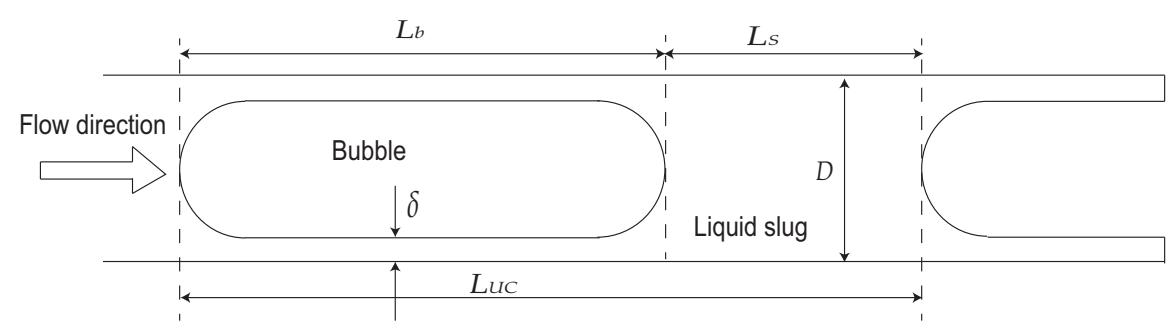

Figure 2: Schematic diagram of a two-phase flow unit cell of slug and bubble.

bubbles. An empirical correlation for the dimensionless liquid film thickness in circular channels was derived based on capillary number, Reynolds number and Weber number at high inertia (refer to Han and Shikazono (2009b) for more details) as shown in equation 5 .

$$
\left[\frac{\delta}{D_{h}}\right]_{\text {steady }}=\frac{0.670 C a^{2 / 3}}{1+3.13 C a^{2 / 3}+0.504 C a^{0.672} R e^{0.589}-0.352 W e^{0.629}}
$$

where, $D_{h}$ is the hydraulic diameter, and $C a<0.3$ and $R e<2000$.

The film thickness for low $C a$ flows in microchannels can be very small; on the order of tens of microns or less which are dimensions that start to push the limits of standard measurement techniques. It has been shown that it is possible to measure micro and nanofilms of fluids using fluorescence microscopy (Hoang et al. (2012)). The temporal resolution is largely determined by the exposure time but is generally too large to capture the transient nature of most two-phase flows in microchannels (Hoang et al. (2012)). Thus, the capabilities of the techniques are restricted by the sensitivity of the camera. Grad et al. (2010) demonstrated the use of optical ring resonators as time-resolved refractive index sensors embedded in microfluidic channels that enables sensing thin liquid films. This technique allows measuring thin films in the range of 250 to 400 nanometers in oil-water two-phase flow systems. 
Optical white light microscopy can also be used to measure the liquid film, although for thicker films (down to about $5 \mu \mathrm{m}$ ). Howard and Walsh extended the range of applicability of Han and Shikazono (2009b) correlation for film thickness prediction from a $C a$ of 0.3 up to 1.9 for gas-liquid twophase flow with a wide selection of liquids for carrier phase. Mac Giolla Eain et al. (2013) measured the film thickness for liquid-liquid slug flow with four different carrier oil/water combinations. They studied the effects of aqueous slug length and carrier phase properties on the magnitude of film thickness and showed the variation of film thickness with upper and lower threshold values of aqueous slug length. Similar to Han and Shikazono (2009b) correlation, the mean slug velocity and the capillary forces exert the greatest influence on the magnitude of liquid film. An overview of some of the recent experimental methods used to measure liquid film thickness are summarised in Table 2, indicating that there is still a need for higher resolution and faster measurement techniques to help understand the thermal boundary associated with a moving slug.

The convective heat transfer rate is intrinsically linked to the thermal boundary layer thickness, which in turn depends on the fluid mechanics of the film (if there is one) between the slug and the wall. Thus the understanding of the mechanics of the transient film thickness is essential for understanding heat and mass transfer enhancement. However, in microchannels it is very difficult to measure the film thickness which can be less than $1 \mu \mathrm{m}$. Therefore, new techniques need to be developed that can measure the transient nature of these films. 


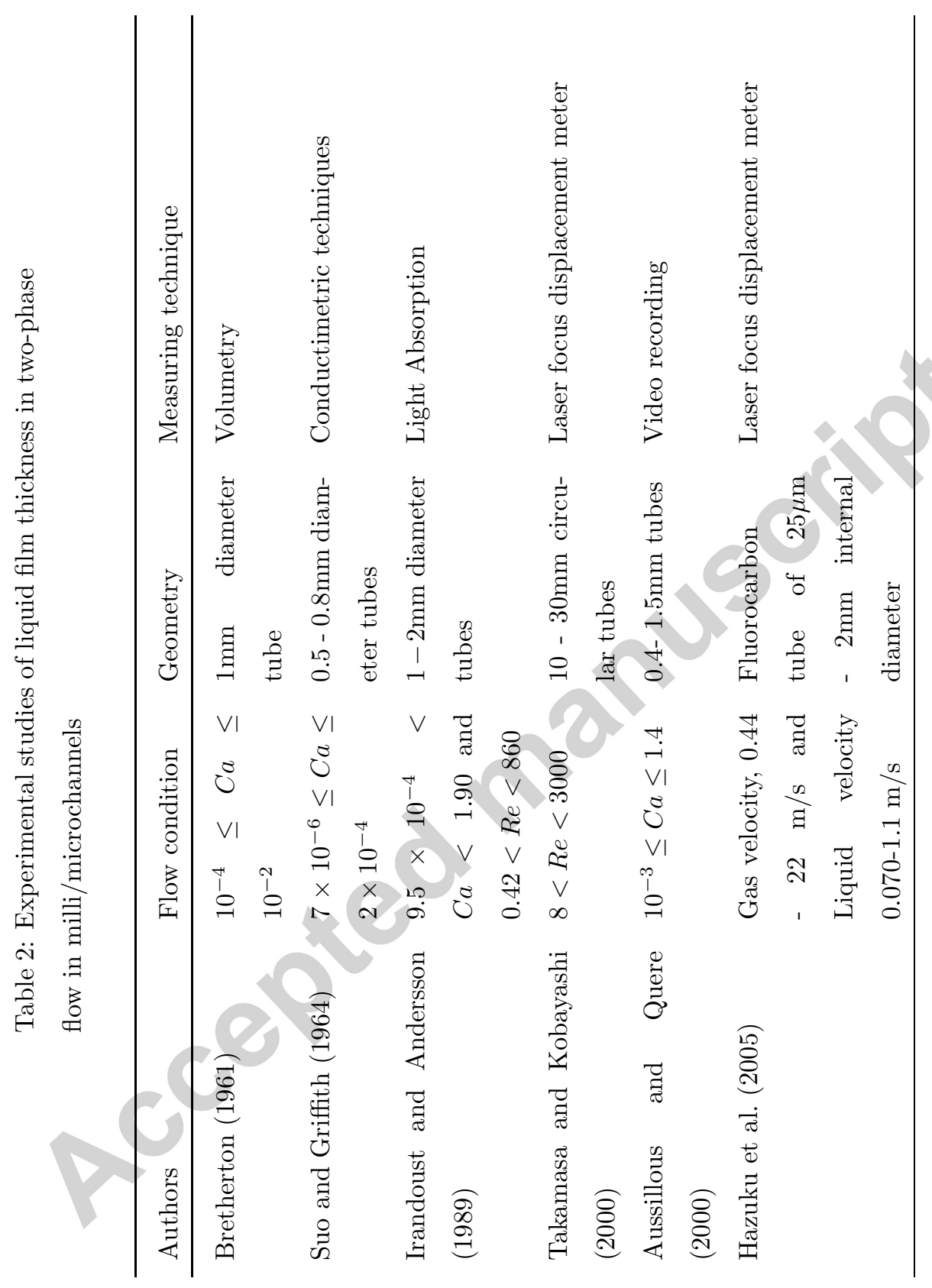




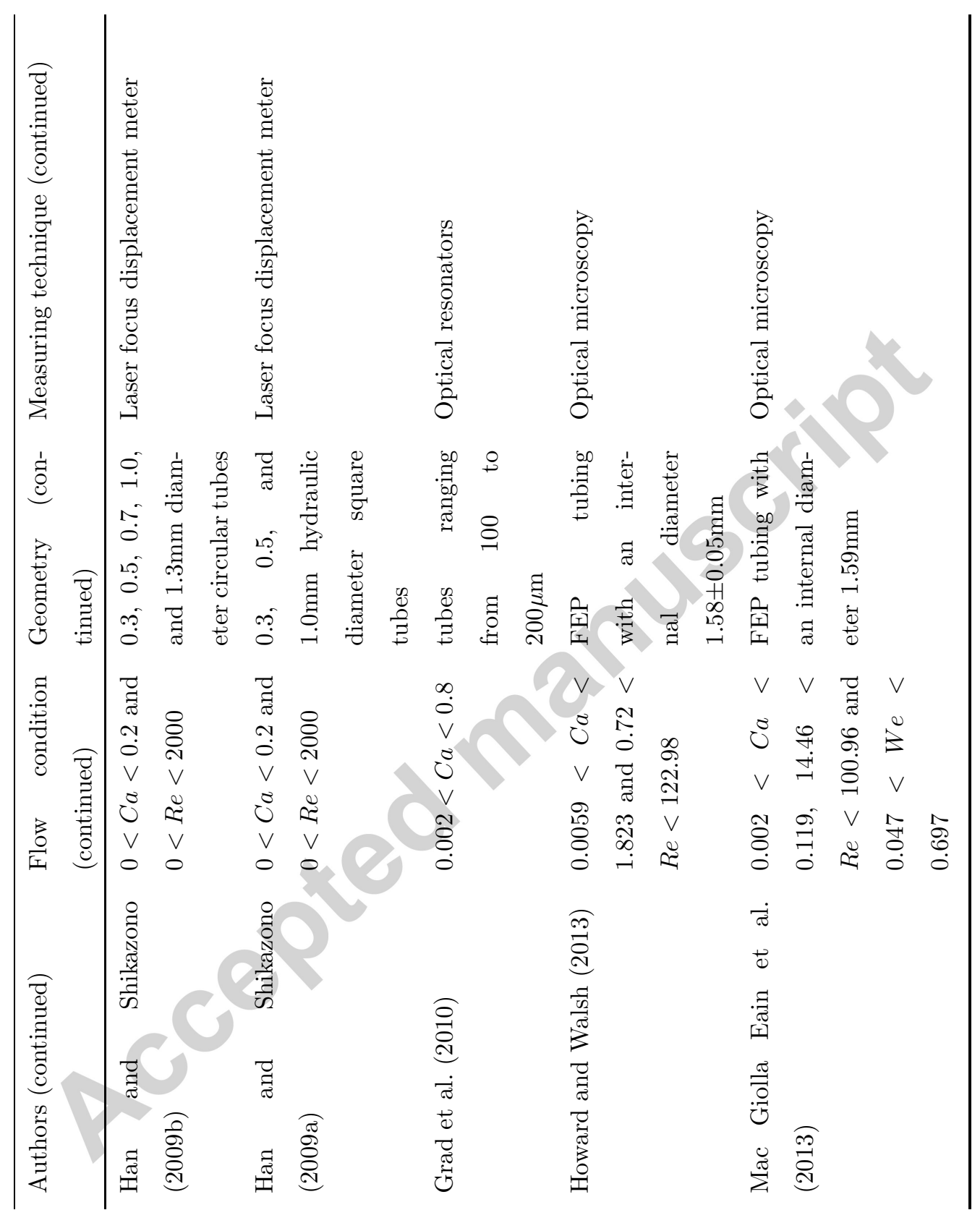




\subsection{Pressure drop}

The pressure drop for two-phase flow in microchannels is significant in terms of system design, parasitic energy loss, pump sizing and flow stability. These effects mean it is important to quantitatively analyse pressure drop in two-phase flow systems using experimental, empirical and semi analytical methods.

Various methods have been developed to determine pressure drop in Taylor flow with none seemingly able to predict over a full range of conditions, not even for laminar flow. The model developed by Lockhart and Martinelli (1949) and the homogenous flow model (Triplett et al. (1999)) have been used as a basis for theoretical correlations using experimental results. However, Liu et al. (2005) reported the incompatibility of the above methods for slugannular flow, annular flow and Taylor flow at relatively low Reynolds numbers due to the flow-regime-independence of those methods. Consequently, an analytical model for the pressure drop in two-phase flow was developed based on the unit cell concept as shown in Figure 2 (Kreutzer et al. (2005b); Walsh et al. (2009)). The total pressure drop, $\Delta P_{t o t}$ in a unit cell comprises of two components: frictional pressure drop in the liquid slug and the pressure drop over the bubble. It is assumed that frictional loss in the liquid film is negligible compared to slug frictional loss, however this analysis neglects cases where the slug touches the wall as $\mathrm{Ca} \rightarrow 0$.

$$
\Delta P_{\text {tot }}=\Delta P_{\text {slug }}+\Delta P_{b u b}
$$

Here $\Delta P_{\text {slug }}$ is the pressure drop in the liquid slug which is the combination of the pressure drop of fully developed laminar flow and the pressure 
drop caused by internal recirculation. The pressure drop across a bubble (interfacial pressure drop), $\Delta P_{b u b}$ is calculated based on the analytical solution introduced by Bretherton (1961), as shown in equation 7. The theory assumes a single gas bubble and takes into account the Laplace pressure from surface tension and the curvature. Viscous forces were assumed to be negligible so it applies when $C a<0.1$.

$$
\Delta P_{b u b}=7.16(3 C a)^{2 / 3} \frac{\sigma}{D}
$$

Kreutzer et al. (2005b) introduced a friction factor for Taylor flow, as shown in equation 8, considering the frictional loss from both liquid slug of length $L_{s}$, and bubble in the unit cell for inertia dominated flows $(\operatorname{Re}=\mathcal{O}(100))$ and lower capillary numbers $(C a=\mathcal{O}(0.01))$.

$$
f=\frac{16}{R e}\left[1+a \frac{D}{L_{s}}\left(\frac{R e}{C a}\right)^{1 / 3}\right]
$$

The value of the $a$ was found to be 0.07 and 0.17 numerically and experimentally respectively. Hence the pressure drop in Taylor flow can be calculated using equation (9).

$$
\frac{\Delta P}{L}=\frac{16}{R e}\left[1+a \frac{D}{L_{s}}\left(\frac{R e}{C a}\right)^{1 / 3}\right] \frac{4}{D}\left(\frac{1}{2} \rho U^{2}\right) \varepsilon_{l}
$$

where $L$ is the length of the channel and $\varepsilon_{l}$ is the volume fraction of primary fluid phase. Kreutzer et al. (2005b) numerically showed that the pressure drop over a bubble increases with increasing Reynolds number and decreasing capillary number. A large oscillation takes place at the rear as shown in Figure 3 due to the presence of increased recirculation around the gas-liquid interface. They selected a unit cell with a gas bubble and two adjacent half 
liquid slugs. However, there are not many cases in microchannels that involve this high inertia regime.

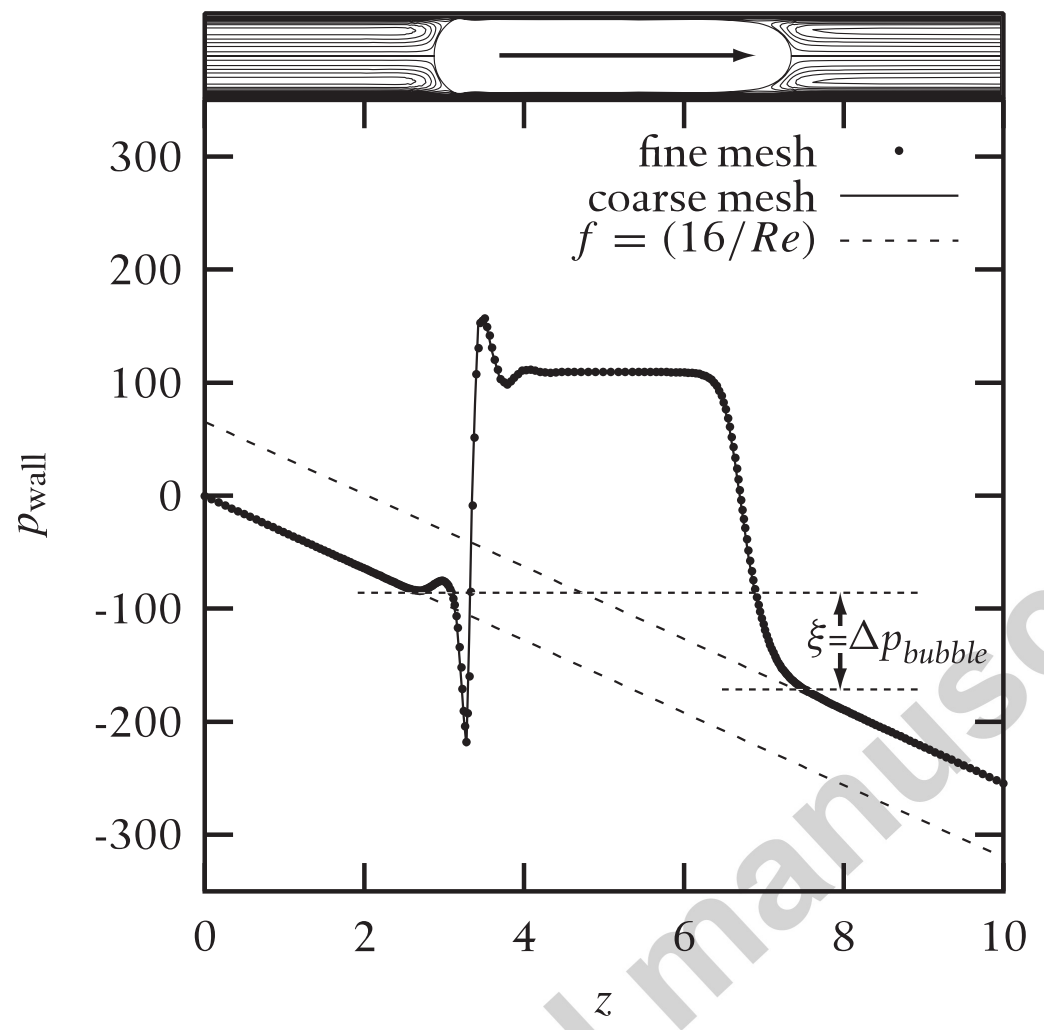

Figure 3: Wall pressure distribution of a unit cell in gas-liquid Taylor flow in the axial direction for $C a=0.01$ and $R e=100$. Dynamic holdup of the liquid (the fraction of channel length occupied by the liquid) in the channel is 0.65 and dimensionless length is 10 (Kreutzer et al. (2005b)).

In an attempt to take into account liquid/liquid two phase pressure drop, Jovanovic et al. (2011) developed a model to analyse the influence of the film velocity on the slug flow pressure drop considering a constant thickness moving film between the secondary phase liquid droplet and the capillary wall in liquid-liquid two-phase flow. The total pressure drop per unit cell was 
broken into three components which are frictional losses in the secondary phase, frictional losses in the primary phase, and the interfacial pressure drop.Thus the pressure drop over a unit length is given as in equation 10 .

$$
\begin{array}{r}
\frac{\triangle P}{L}=\frac{4 U_{s} \beta}{\left(R^{2}-(R-\delta)^{2}\right) / \mu_{p}+\left(0.5(R-\delta)^{2}\right) / \mu_{s}}+\frac{8 U_{T P}(1-\beta) \mu_{p}}{R^{2}} \\
+\frac{7.16}{L_{U C}}(3 C a)^{2 / 3} \frac{\sigma}{D}
\end{array}
$$

where, $\beta, \mu_{p}, \mu_{s}, U_{T P}, U_{s}$, and $L_{U C}$ are void fraction, viscosity of primary phase, viscosity of secondary phase, mixture velocity, secondary phase velocity and unit cell length respectively.

Most recently Eain et al. (2013) pointed out the lack of data or consistent correlations for Taylor flow pressure drop. They commented on the wide range of values calculated for identical flow conditions, citing the lack of taking into account the flow physics when developing the models for the discrepancy, particulary liquid/liquid flows. They developed a correlation for the skin friction coefficient, $C_{f}$, where the pressure drop is $\Delta P=0.5\left(C_{f}\right) \rho U^{2}$. $C_{f}$ is in terms of the non-dimensional length, the capillary number and the Reynolds number, and is given by equation 11

$$
C_{f}=14.486\left[\left(L_{s}^{*}\right)^{0.65} \times\left(C a_{p}\right)^{-0.616} \times\left(R e_{p}\right)^{-1.05}\right]
$$

where, $p$ and $s$ denote the primary and secondary phase respectively. While it fits their data quite well there is still a long way to go. Figure 4 shows the variation of pressure drop with Reynolds number for a liquid-liquid two-phase flow system in a $800 \mu \mathrm{m}$ diameter microchannel, calculated using pressure drop correlations discussed above. The calculated pressure drop values using the correlations using similar flow conditions clearly do not agree with each other. However, it should be noted that each correlation has a different 
uncertainty associated with it (refer to original studies). Compared to gasliquid two phase flow, liquid-liquid two phase flow research is still relatively immature leaving to gaps in some of the fundamental physics.

Heat and mass transfer enhancement almost always comes with the penalty of increased pressure drop which is detrimental to a system as the pumping energy is higher. Thus any study of heat and mass transfer increase must have data on the pressure drop increase to ensure a balance is reached between the increase in heat and mass transfer rate and the increased pumping power.

\subsection{Void fraction}

The percentage of the flow domain occupied by the secondary phase (bubble or droplet) in two-phase flow is known as the void fraction. Void fraction is the key parameter of determining other flow parameters in slug flow, namely two-phase density and slug and droplet/bubble velocities. It is also very important in terms of heat transfer, flow pattern transition and pressure drop as the two phases invariably have different viscosity and thermal conductivity. The void fraction, $\beta$ is the volume of space occupied by the each phases such that, $\beta=Q_{s} /\left(Q_{p}+Q_{s}\right)$. However, determining the void fraction based on inlet flow conditions can be misleading, due to the slippage between the two fluid phases (Woldesemayat and Ghajar (2007)).

It can be challenging to measure the void fraction in micro scale flow systems, and most of the experimental measurements in the literature have been done using flow visualization or conductivity techniques (Gupta et al. (2010b)). In conductivity measurements, the impedance between two electrodes in contact with fluid is measured, as the bulk impedance depends 


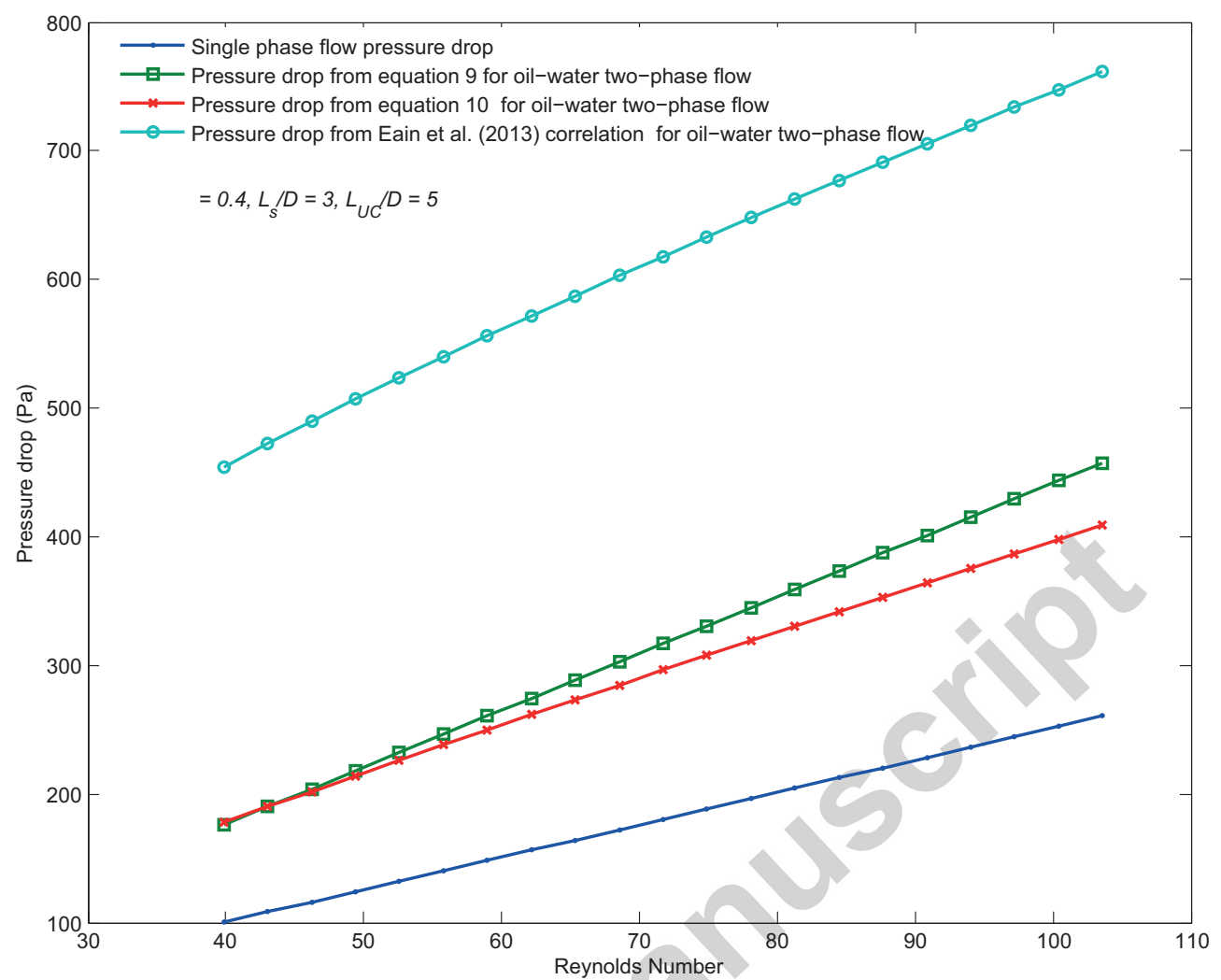

Figure 4: Variation of pressure drop with Reynolds number in a circular microchannels of diameter $800 \mu \mathrm{m}$ with a length of $50 D$ based on different pressure drop correlations from the literature (equation 9, equation 10 and correlation in Eain et al. (2013)). The data points are generated using the values and relationships shown in the Table 3 for a liquid-liquid two-phase flow with water as primary fluid and silicon as secondary fluid.

upon the relative concentrations of two phases (Ceccio and George (1996); Tsochatzidis et al. (1992)). The void fraction for air-water two-phase flow in microchannels has been measured successfully using this technique Kariyasaki et al. (1991), Bao et al. (1994), Mishima and Hibiki (1996), Triplett et al. (1999), Serizawa et al. (2002), and Kawahara et al. (2002).

The experimental results obtained by Bao et al. (1994) showed a good 
agreement with Lockhart and Martinelli (1949) and CISE (Premoli et al. (1970)) correlations which were extrapolated from macro-scale models. Triplett et al. (1999) found that their experimental data of void fraction in bubbly and slug flow agreed well with the prediction from the homogeneous flow model. Data obtained by Serizawa et al. (2002) was in good agreement with the Armand correlation (Armand and Treschev (1946)) unlike the Kawahara et al. (2002) results. In the experimental studies by Godbole et al. (2011) in an upward vertical two-phase flow system, the void fraction correlations were compared with the existing correlations in the literature, and best void fraction correlations were highlighted for four different ranges of void fraction. A flow pattern independent drift flux model based void fraction correlation was developed in the most recent experimental studies by Bhagwat and Ghajar (2014). A comprehensive list of correlations for void fraction can be found in Godbole et al. (2011). These experimental studies have become a strong foundation for two-phase flow studies. Void fraction is an important parameter in the description of slug/Taylor flow and should be taken into account when describing above conditions. Again most of the studies have been carried out for gas-liquid two-phase flow with a noticeable few on liquid-liquid flow.

The void fraction is particularly relevant to heat transfer when there is a marked difference between the thermal conductivity of the two phases. For example liquid/gas systems or aqueous/metal liquid systems.

\subsection{Wall wettability and contact angle}

Surface wettability plays a key role in droplet formation in microchannels and in the droplet shape with two-phase flow, when the bubble or droplet 
touches the wall (sliding slug). The interface shape of a sliding slug is a function of the viscous deformation force, the surface tension force and contact angle. The first two forces are taken into account with the Capillary number but contact angle is not considered except in a couple of studies (Bandara et al. (2014)).

Wetting is categorised into four regimes which are, completely wetting (when $\theta=0^{0}$ and liquid spreads completely over the solid also called superhydrophilic surfaces), wetting (when $0^{0}<\theta<90^{\circ}$ and liquid spreads partially over the solid), non wetting (when $90^{\circ}<\theta \geq 150^{\circ}$ and liquid spread partially over the solid), and super-hydrophobic (when $\theta>150^{\circ}$ (Shirtcliffe et al. (2010); Rosengarten et al. (2011))). Experimental observations reveal that most material systems typically exhibit contact angle hysteresis (Shao (2010)) i.e., the contact angle depends on which directions the interface is moving. This is important in sliding slug flow as the front and rear of the bubble will have different contact angles when the slug is attached to the wall.

A slug (diameter larger than the channel diameter) at rest for a sufficient amount of time for the liquid film to be drained, will wet the wall. If that slug is then accelerated (increased Capillary number) the slug will eventually detach from the wall. The effect of capillary number on contact angle for a bubble in a small channel is illustrated in Figure 5. Initially the interface will have a given static angle, $\theta$, at zero velocity (Figure 5a). With the external pressure force the bubble will move and the front and back contact angles start to change as a function of $C a$. This will create a receding $\left(\theta_{\text {rec }}\right)$ and an advancing $\left(\theta_{a d v}\right)$ angle as shown in Figure $5 \mathrm{~b}$. With the increment of $C a$, 
the viscous force become significant, the dynamic contact angle increases and the slug separates from the wall as shown in Figure 5c. A continuous phase films forms between the wall and the slug interface and grows until the discrete phase is completely separated from the wall as show in the Figure 5 d. This separating liquid film may be very thin $(<100 \mathrm{~nm}$ depending on the channel diameter and capillary number) and sometimes it is hard to determine whether it exists or not. Therefore, an apparent contact angle $\left(\theta_{\text {aprnt }}\right)$ is introduced as shown in the Figure $5 \mathrm{~d}$.

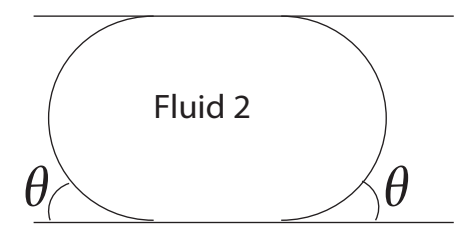

(a)

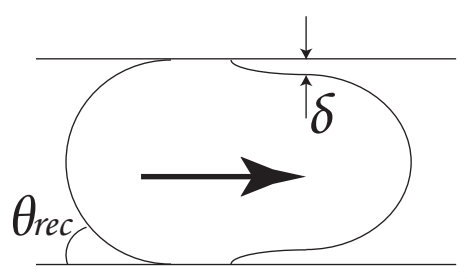

(c)

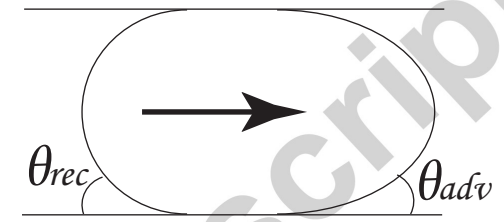

(b)

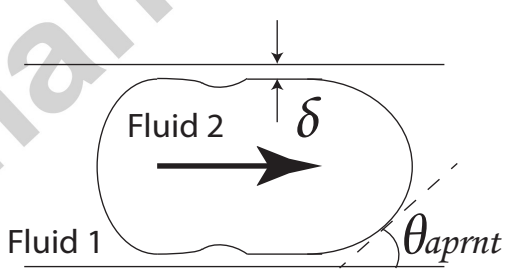

(d)

Figure 5: Schematic of the progression in the wetting behavior of bubbles at increasing $\mathrm{Ca}$ showing advancing and receding contact angles and film thickness such that (a) static contact angles, (b) dynamic contact angles, (c) de-wetting initiation and (d) complete detachment of formation of liquid film.

The experimental and numerical studies carried out by Rosengarten et al. (2006) demonstrate the droplet behavior in a sudden contraction. Furthermore, they highlight the role the contact angle plays when the liquid film 
surrounding the bubble becomes very thin and can be influenced by long range of van der Waal forces. The contact angle in two-phase slug flow microchannels is important because it affects the shape of the slug and the slug velocities in the channel particularly at low Ca. Santos and Kawaji (2010) reported the effect of the contact angle on flow formation as shown in Figure 6. This effect is significant in microchannels, where surface tension becomes significant due to the smaller diameters. As the contact angle affects the length and speed of the slug which in turn will influence the heat and mass transfer.

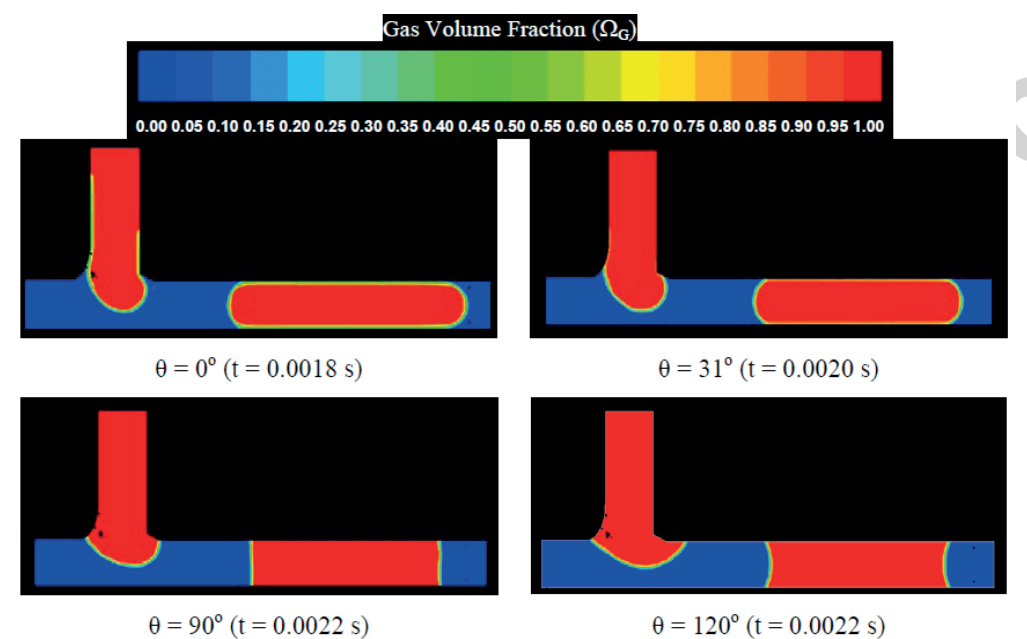

Figure 6: Effect of contact angle on slug formation in gas-liquid two-phase flow in a Tjunction (Using CFD) (Santos and Kawaji (2010)).

\section{Two-phase flow heat transfer}

There has been considerable research on the relationship between the heat transfer rate and the hydrodynamics of two-phase flow both experimentally 
and numerically. The heat transfer coefficient on channel walls can be nondimensionalized into local Nusselt number $\left(N u_{x}\right)$ which is defined as

$$
N u_{x}=\frac{q D_{h}}{k\left(T_{w}-T_{m}\right)}=\frac{h D_{h}}{k}
$$

where $q, T_{w}$ and $T_{m}$ are heat flux, wall temperature, and mean flow temperature respectively. The mean Nusselt number can be calculated by integrating the Nusselt number over the non dimensional duct length.

$$
\overline{N u}=\frac{1}{L^{*}} \int_{0}^{L^{*}} N u_{x} d x=\frac{\bar{q} D_{h}}{k \triangle T}
$$

where $L^{*}$ is the non-dimensional channel length and $\bar{q}$ is the mean heat flux. The value, $k$ is thermal conductivity of the primary phase.Various $\mathrm{Nu}$ correlations in terms of the flow parameters have been developed, however, as will be shown, the agreement in the values from the heat transfer correlations is far from good.

\subsection{Gas-liquid two-phase flow heat transfer}

Oliver and Wright (1964) experimentally investigated the effect of void fraction on two-phase flow heat transfer for both Newtonian and non-Newtonian fluids for a constant wall temperature. However, they could not control the slug length due to the experimental limitations. The follow up work by Oliver and Young Hoon (1968) reported the effect of slug length on heat transfer. A number of researchers extended this work and suggested expressions for

the Nusselt number based on parameters such as channel diameter, heating length, and slug length (Leung et al. (2010)) (refer to section 3.3). Walsh et al. (2010) also studied the effect of slug length on heat transfer and they identified an entrance region of about one slug length for which initially high 
values of the Nusselt number relaxed towards a constant asymptotic value similar to single phase flow. Numerical investigations of heat transfer in slug flow with constant wall heat flux have been carried out revealing that the overall heat transfer coefficient is largely controlled by the value for the slug region and the fraction of the wall occupied by the slug (He et al. (2010)). Importantly this is different to the controlling variables for the pressure drop.

In recent experimental work by Leung et al. (2010), the dependency of the hydrodynamic characteristics (mixture velocity, homogeneous void fraction and liquid film thickness) on heat transfer rate for gas-liquid Taylor flow was investigated. They extended these experiments in their followup work and analyzed the heat transfer characteristics for three different fluids as the liquid phase.They also used a wide range of capillary numbers $(0.001<C a<0.190)$ for the experiments in order to study the underlying control mechanism in two-phase flow heat transfer. They concluded that the size of the recirculation zone and the recirculation efficiency, which are important parameters for Taylor flow heat transfer, are strong functions of capillary number (Leung et al. (2012a)). Further more, they revealed that the liquid film thickness around the gas bubble significantly influences heat transfer performance. In their most recent work Leung et al. (2012b) studied the gravitational effect on Taylor flow in horizontal microchannels with gas-liquid, and showed that there is only a minor effect of gravity on heat transfer rate.

Recently, Howard et al. experimentally examined the effect of Prandtl and capillary numbers on heat transfer performance in gas-liquid two-phase flow microchannels (Howard et al. (2011)). They showed a 600\% enhance- 
ment in heat transfer rates over conventional Poiseuille flow which was applicable for Nusselt number over inverse Graetz number $(G r=D P e / x$, $P e=U D / \kappa$ where, $x$ is the length, and $\kappa$ is the thermal diffusivity) ranges from $10^{-4}$ to 1 and slug length to channel diameter ratio from 0.88 to 32 . The effect of channel diameter on heat transfer $(145,190,303$, and $506 \mu \mathrm{m}$ channels) and pressure drop was studied experimentally by Choo and Kim (2011) for a gas-liquid two-phase flow in stainless steel microchannels. They studied the heat transfer characteristics by keeping the water flow rate constant and varying the air flow rate. They showed that the Nusselt number increased with increasing gas flow rates for the larger diameter channels, due to the presence of turbulent mixing in the liquid film. However, they used different types of flow regimes other than slug flow in heat transfer experiments due to the high Reynolds number flows. Experimental studies by Majumder et al. (2013) showed a 1.2 - 1.6 times heat transfer enhancement with gas-liquid Taylor flow in square mini channel. They observed the temporal fluctuations of the fluid temperature using embedded-thermocouples but no fluctuations in the wall temperature due to the relatively large thermal mass of the wall. In the recent experimental studies by Lim et. al (Lim et al. (2013)), the pressure drop variation was studied under adiabatic and heat transfer conditions and revealed a significant decrease of pressure drop under the heat transfer condition due to the change in fluid viscosity in a gasliquid two-phase flow system. They also presented an optimal heat transfer condition for the two-phase flow, is to keep the bubble diameter close to the channel diameter and the void fraction to be around $10 \%$. They showed a $176 \%$ maximum thermal performance enhancement under these conditions. 
Temperature measurements in microchannels is very challenging due to the relative size of transducers, such as thermocouples, compared to the channel. Thus infrared (IR) thermography has become popular (Carlomagno and Cardone (2010); Howard et al. (2011); Mehta and Khandekar (2014)).

The geometry of the channel cross section also plays an important role in hydrodynamics and heat transfer performance. In microchannels particularly due to different fabrication methods, the cross section of the microchannels may be circular, square, rectangular, triangular, elliptical and trapezoidal etc. (Bahrami et al. (2007)) which affects the film thickness and uniformity.

Even though gas-liquid two-phase flow has large impact on heat removal there are drawbacks and limitations. A drawback of the introduction of gas bubbles into the liquid flow is the decrease of the flow-averaged values of the thermodynamic properties of the gas-liquid medium due to the low thermal conductivity and heat capacity of the gas compared to those of the liquid (Asthana et al. (2011)). The introduction of immiscible liquid droplets with higher heat capacity and conductivity has the potential to overcome these problems.

\subsection{Liquid-liquid two-phase flow heat transfer}

Liquid-liquid two phase flow offers the highest potential for heat transfer enhancement due to the inherently higher thermal conductivity of liquids compared to gases. This can become marked for very high thermal conductivity liquids such as metals and nanofluids. The flow characteristic such as flow patterns and pressure drop of liquid-liquid two-phase flow in microchannels are still not well understood, and limited research work has been carried out (Jovanovic et al. (2011); Foroughi and Kawaji (2010); Salim et al. 
(2008)). However, various investigations have been carried out on viscous oilwater flows in small and conventional horizontal/vertical pipes (Foroughi and Kawaji (2010)). The interest of studying on oil-water two-phase flow in microchannels was driven by applications of microfluidic devices with precisely controlled droplet size and polydispersity in creating emulsions commonly used the chemical, textile, food and other industries (Salim et al. (2008)).

\subsubsection{Hydrodynamics}

While there has been significant research work in the literature on applications of liquid-liquid two-phase flow, generally related to lab on a chip and individual droplet reactors we do not aim to cover this area extensively in this review. A few recent examples include Zhao (2013), Howard and Walsh (2013) and Rosenfeld et al. (2014). Dreyfus et al. revealed the controllability of flow patterns by the wetting properties of the fluid, in their droplet formation experiments (Foroughi and Kawaji (2010, 2011); Dreyfus et al. (2003)). However, the injection method used by Foroughi and Kawaji may not be stable as in a T-junction or other flow focusing devices. Kashid and Agar (2007) investigated the effect of various operating conditions on the flow patterns, slug size, interfacial area, and pressure drop in a Y-junction microchannel. Pressure drop, flow patterns and wettability of oil-water two-phase flow in microchannels were studied by Salim et al. (2008). They carried out experiments for quartz and glass microchannels initially saturated with oil and microchannels initially saturated with water. They visualized different flow patterns in two different channels when the channel was initially saturated with water. While they had droplet, slugs, and stratified flows for the quartz microchannels, slugs, semi-stratified, and stratified flows were observed in 
glass channels. This indicates the importance of surface forces in two-phase flow. Foroughi and Kawaji (2011) conducted experiments on two liquids in microchannels in order to form droplets or plugs, and observed different types of flow patterns and the associated pressure drop.

\subsubsection{Heat transfer}

While wall to liquid heat transfer during slug/Taylor flow in microchannels has been studied numerically, there has only been one experimental study to date (Asthana et al. (2011)). Heat transfer enhancement in mineral oil carrying water droplets in micro-tubes was numerically investigated by Ur-

brant et al. (2008) and they revealed improvement of Nusselt number caused by the flow interruption in the carrier flow and the internal circulation within the droplets (Asthana et al. (2011)). The effect of slug size on heat transfer also was investigated, showing increased droplet size yields more efficient heat transfer and higher values of Nusselt number. Numerical simulations of immiscible fluids with water as the carrying fluid were investigated by Fischer et al. (2010). Their simulations also included nano-particles in the secondary phase fluid and included Marangoni and colloidal effects. They showed that the use of a second suspended liquid (with or without nano-particles) is an efficient way to improve the heat transfer without unacceptably high pressure losses. They also reported a 400\% increase in the magnitude of Nusselt number relative to single-phase flow in the case of slug-train coflow. Recent experimental work carried out by Asthana et al. (2011) investigated the heat transfer enhancement in microchannels with liquid-liquid two-phase flow. A serpentine microchannel was utilized for their experiments and heat transfer between single-phase liquid and segmented liquid-liquid flow was compared. 
The comparison was performed using the measurements of local temperature, and velocity and pressure drop at various flow rates. Using Laser Induced Fluorescence(LIF) for measuring temperature and micro-PIV(Particle Image Velocimetry) for velocity measurements, they demonstrated a four-fold Nusselt number improvement in slug flow compared to that with pure water.

\subsection{Nusselt number correlations}

Heat transfer in a two-phase flow system depends on factors such as flow conditions (particularly near the walls), geometry of the channel, and properties of the fluids. Thus, a model developed based on the average flow properties of the two-phases is not sufficient to describe the underlying physics of the phenomena. It is necessary to carefully consider the near-wall and bulk fluid properties. Consequently, theoretical models have been developed based on different flow conditions and flow parameters to explain the heat transfer behavior in two-phase flow. Che et al. (2011, 2012, 2013) developed analytical and numerical models for mass and heat transfer of plug flow in cylindrical capillaries. These works predicted one order of magnitude improvement for the heat transfer coefficient using plug flow without phase change.

Experimental work carried out by different research groups has clearly shown a significant increases in two-phase flow heat transfer relative to that for single phase flow. Theoretical models have also been developed to correlate experimental data. Oliver and Wright (1964) introduced a model, which is a modification to Gratez-Leveque solution for thermally developing laminar flow, to explain their experimental results that reportedly showed 2.5 times heat transfer enhancement. The model was in the form of a Nusselt 
number, $N u$, given by

$$
N u=1.615\left(\operatorname{Re} \operatorname{Pr} \frac{D}{L}\right)^{1 / 3}\left(\frac{1.2}{(1-\beta)^{0.36}}-\frac{0.2}{1-\beta}\right)\left(\frac{\mu_{B}}{\mu_{W}}\right)^{0.14}
$$

where $\mu_{B}$ and $\mu_{W}$ are the liquid viscosities at bulk fluid temperature and the heat transfer boundary temperature respectively. $L$ is the heated length of the channel. However, there was no quantitative explanation on effects of slug length on heat transfer due to the experimental limitation of controlling of slug lengths. A modification of the Graetz-Leveque solution considering the fraction of the cross section occupied by liquid (in gas-liquid flow) for a thermally developing laminar flow proposed by Hughmark (1965) is

$$
N u \sqrt{1-\beta}=1.75\left(\operatorname{Re} \operatorname{Pr} \frac{D}{L}\right)^{1 / 3}\left(\frac{\mu_{B}}{\mu_{W}}\right)^{0.14} .
$$

A Nusselt number correlation for the slug region $\left(N u_{s}\right)$ based on the slug length was proposed by Kreutzer et al. (2001) to represent their results of twodimensional CFD simulations. A wide range of conditions $\left(1<L_{s} / D<16\right.$, $7<\operatorname{Pr}<700,10<\operatorname{Re}<400$ ) for two-phase flow in a $1 \mathrm{~mm}$ diameter tube were considered in their simulations, with their correlation given as

$$
N u_{s}=20\left[1+0.003\left(\frac{L_{s}}{\operatorname{RePr} D}\right)^{-0.7}\right]
$$

As discussed in section 3.3, Walsh et al. (2010) developed a correlation for the Nusselt number based on slug length which is given as

$$
N u=(1-\beta)\left[N u_{s p}+25\left(\frac{L_{s}}{D}\right)^{-0.5}\right]
$$

where $N u_{s p}$ is the fully developed liquid-only (single phase) Nusselt number for constant heat flux conditions. In this study they used a wide range of 
values for $C a$ and Re numbers $\left(6.6 \times 10^{-4}<C a<8.8 \times 10^{-3}\right.$ and $56.4<$ $R e<1127)$ and identified that the effective heat transfer area is the part of the wall covered by the liquid slugs but not by the gas bubbles.

Following a similar method to Walsh et al. (2010), Leung et al. (2010) argued that characteristic length in heat transfer calculations should be slug length, rather than the total length from the entrance, and correlated their experimental results to an apparent slug Nusselt number as a function of the dimensionless slug length as given in equation 18 .

$$
N u_{L^{*}}=4.364+\frac{0.29}{L_{s}^{*}+0.15 L_{s}^{* 1 / 3}}
$$

Apparent slug Nusselt number, $N u_{L^{*}}$ is related to Nusselt number as

$$
N u_{L^{*}}=N u \frac{L_{U C}}{L_{s}}
$$

where $L_{U C}$ is the length of unit cell. $L_{s}^{*}=\frac{L_{s}}{\operatorname{RePrD}}$ is the dimensionless slug length.

Unfortunately, there is little agreement in the literature in terms of heat transfer as these correlations give widely varying values of the Nusselt number for identical conditions. In order to demonstrate the variation, the Nusselt number is plotted as a function of the Reynolds number and void fraction for liquid-liquid two-phase flow in a circular microchannel as shown in Figure 7 (a) and (b), calculated using above correlations. A circular channels of diameter $800 \mu \mathrm{m}$ with heating length, $L=50 \mathrm{D}$ is used to illustrate the variation in predicted Nusselt number for the arbitrary flow conditions generated for a liquid-liquid two-phase flow system. The flow rate of primary phase (water) is varied from $1206-2413 \mu \mathrm{l} / \mathrm{min}$, with secondary phase (silicon 
oil) flow rates of $302-2715 \mu \mathrm{l} / \mathrm{min}$. The slug length to hydraulic diameter ratio, $L_{s} / D=3$ and unit cell length to diameter ratio, $L_{U C} / D=5$ are maintained constant for both Nusselt number against Reynolds number and Nusselt number against void fraction calculations. Homogeneous void fraction is calculated using $\beta=U_{s} /\left(U_{p}+U_{s}\right)$ where $U_{p}$ is the velocity of primary fluid and $U_{s}$ is the velocity of secondary fluid. Reynolds and capillary numbers are calculated based on the two-phase velocity, $U_{T P}=U_{p}+U_{s}$. The Nusselt number for fully-developed single-phase flow is 4.36 for a circular channel flow with constant heat flux boundary conditions. As Figure 7 shows most correlations show a significant increase in Nusselt number relative to single-phase flow, however there is a massive difference in the values. These differences could be due to; differences in boundary conditions used in each study, accuracies related to temperature measurements used during correlation development, surface effects that were not taken into account, or the parameters are beyond the limits for which the correlations were developed. However, there are more interrelated parameters that affect heat transfer rates than the current correlations taken into account.

A summary of the key heat transfer studies in two-phase flow is given in Table 4 . 


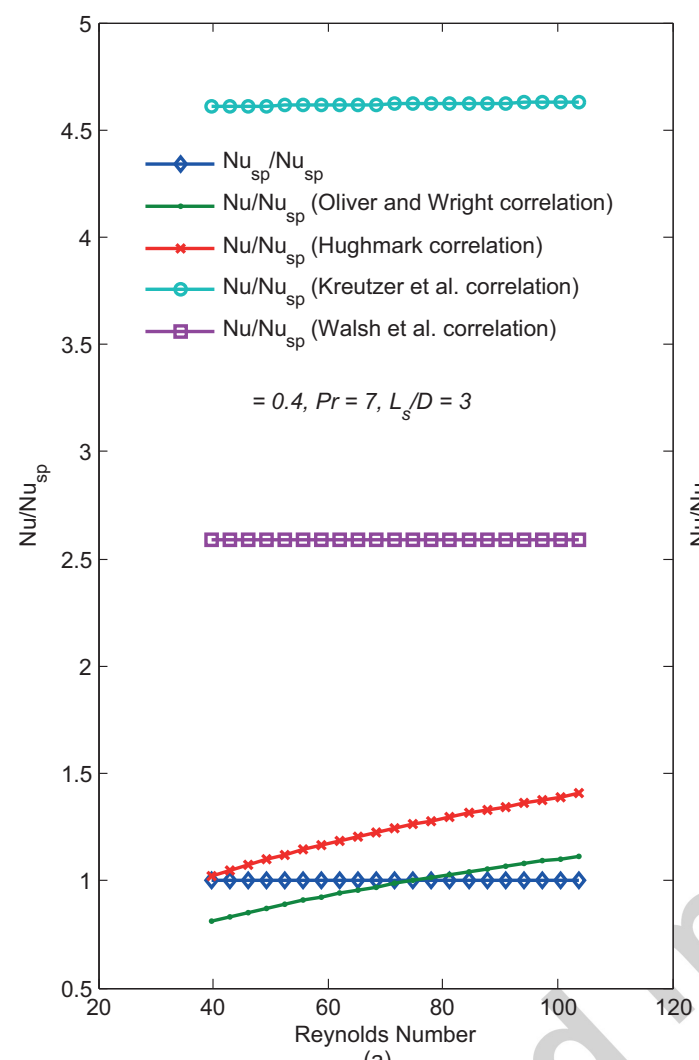

(a)

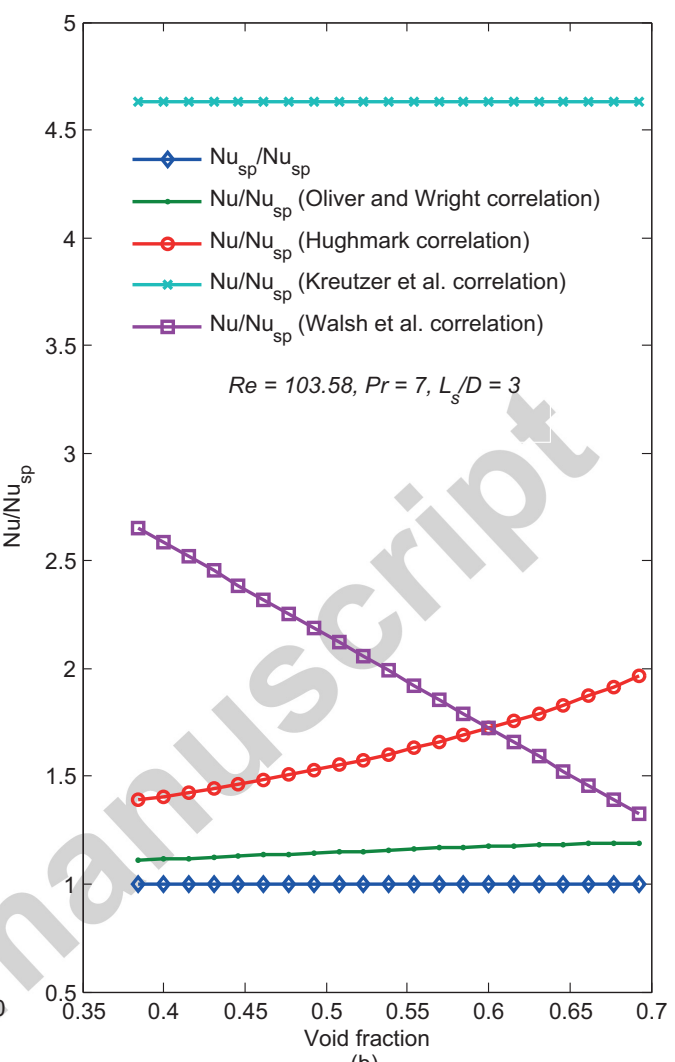

(b)

Figure 7: Variation of Nusselt number (nondimensionalized with respect to single phase) with Reynolds number and void fraction in a circular microchannels of diameter $800 \mu \mathrm{m}$ based on different correlations from the literature (Oliver and Wright (1964); Hughmark (1965); Kreutzer et al. (2001); Walsh et al. (2010)). The parameters (ratio of flow rates and slug lengths) are selected arbitrarily for a liquid-liquid two-phase flow with water as primary fluid and silicon oil as secondary fluid. The data points are generated using the values and relationships shown in the Table 3 
Table 3: Different parameters and data values used for the Nusselt number calculations in Figure 7

\begin{tabular}{|c|c|}
\hline Parameter & Calculation method \\
\hline Water flow rates & $1206-2413 \mu \mathrm{l} / \mathrm{min}$ \\
\hline Silicon oil flow rate & $302-2715 \mu \mathrm{l} / \mathrm{min}$ \\
\hline Mixture velocity & $U_{T P}=U_{p}+U_{s}$ \\
\hline Homogeneous void fraction & $\beta=\frac{U_{s}}{U_{p}+U_{s}}$ \\
\hline Capillary number & $C a=\frac{\mu_{p} U_{T P}}{\sigma}$ \\
\hline Reynolds number & $R e=\frac{\rho_{p} U_{T P} D}{\mu_{p}}$ \\
\hline Single phase Nusselt number & 4.36 for constant hea \\
\hline Viscosity of water & $\mu_{p}=0.001002$ Pa.s \\
\hline Kinematic viscosity of silicon oil & $\nu_{s}=1.5 \mathrm{cSt}$ \\
\hline Interfacial tension of water/silicon oil & $\sigma=0.036 \mathrm{~N} / \mathrm{m}$ \\
\hline Prandtl Number & $\operatorname{Pr}=\frac{C_{p} \mu_{p}}{k}$ \\
\hline Slug length to diameter ratio & $L_{s} / D=3$ \\
\hline Unit cell length to diameter ratio & $L_{U C} / D=5$ \\
\hline
\end{tabular}




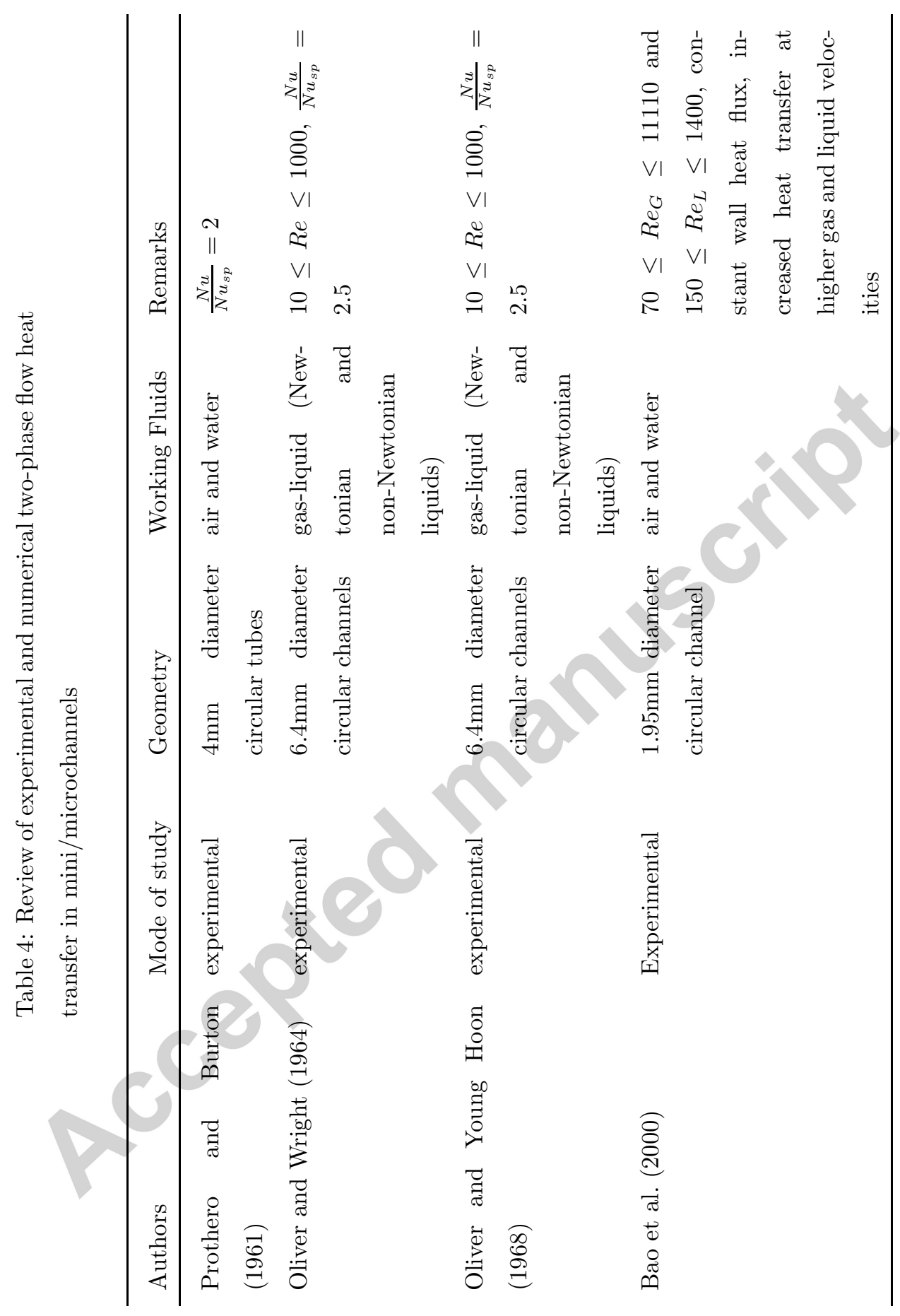




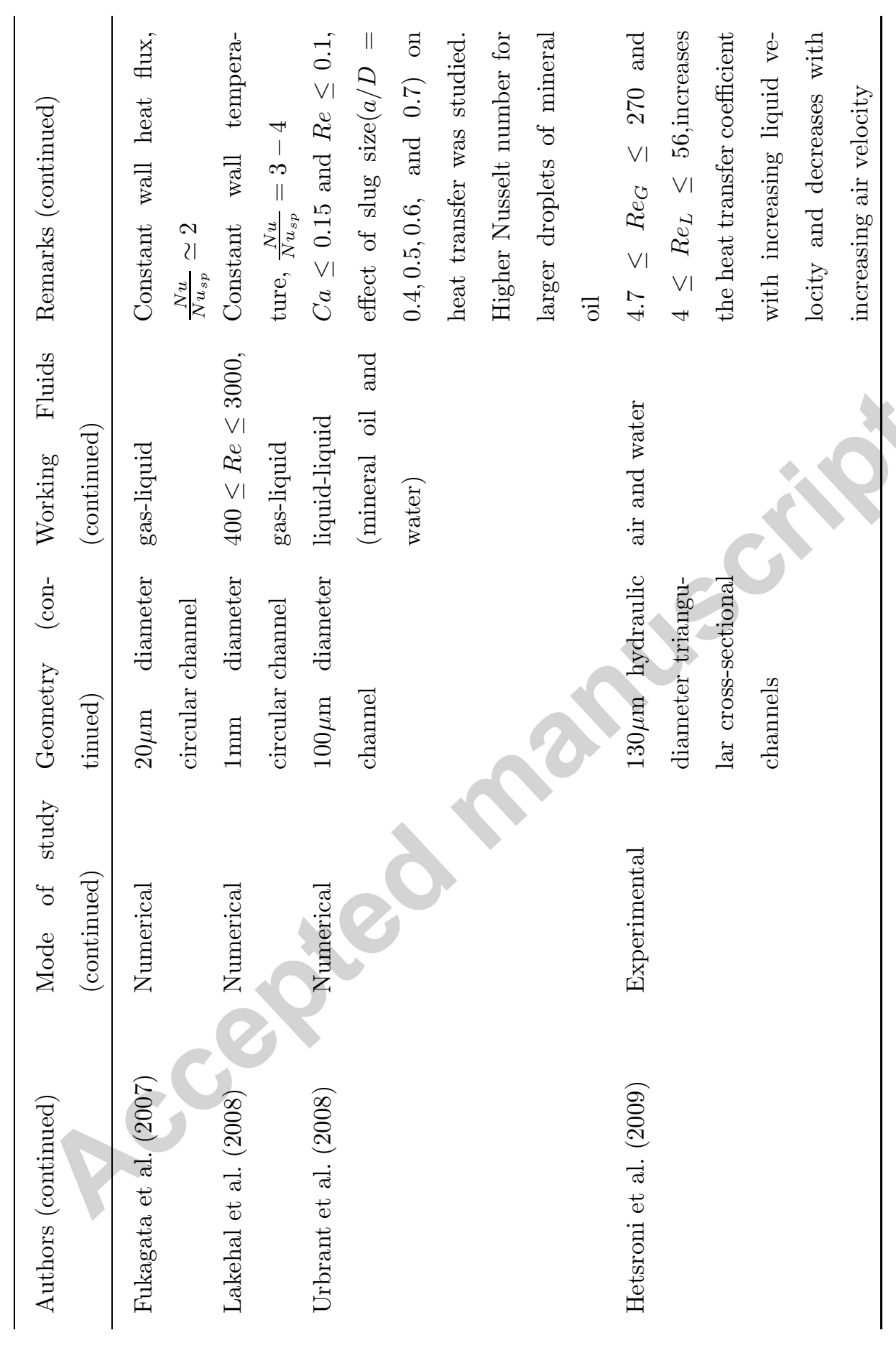




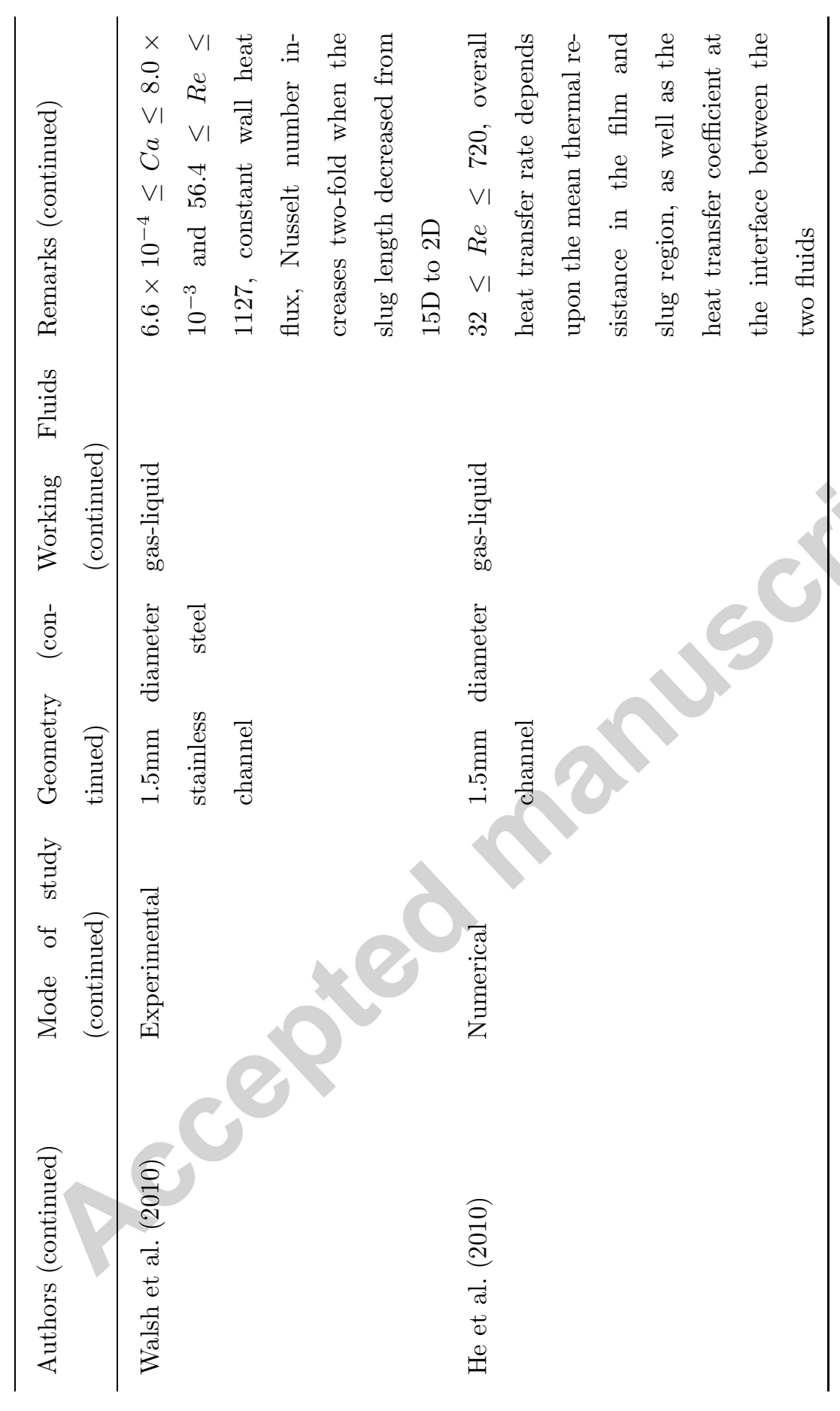




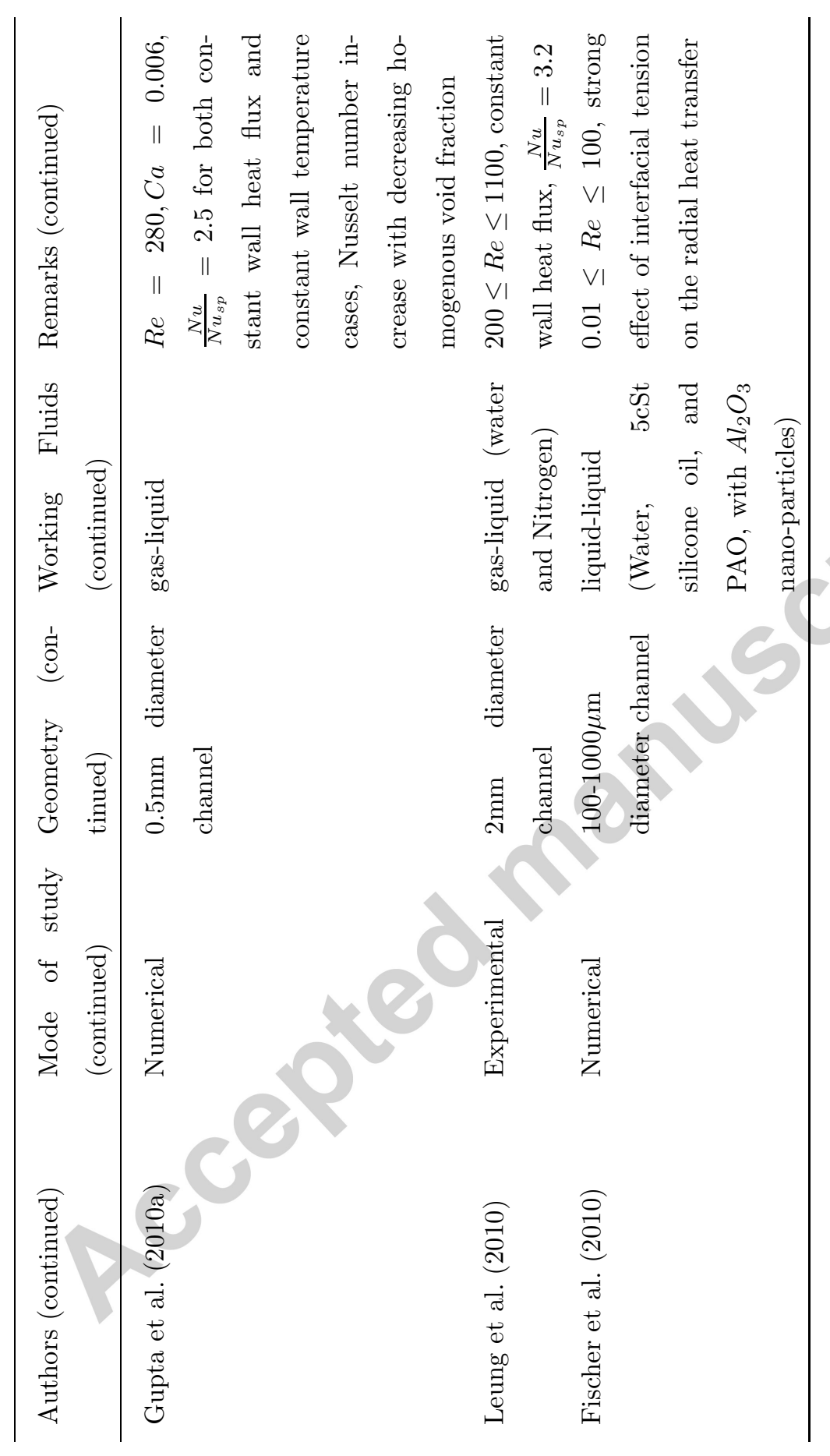




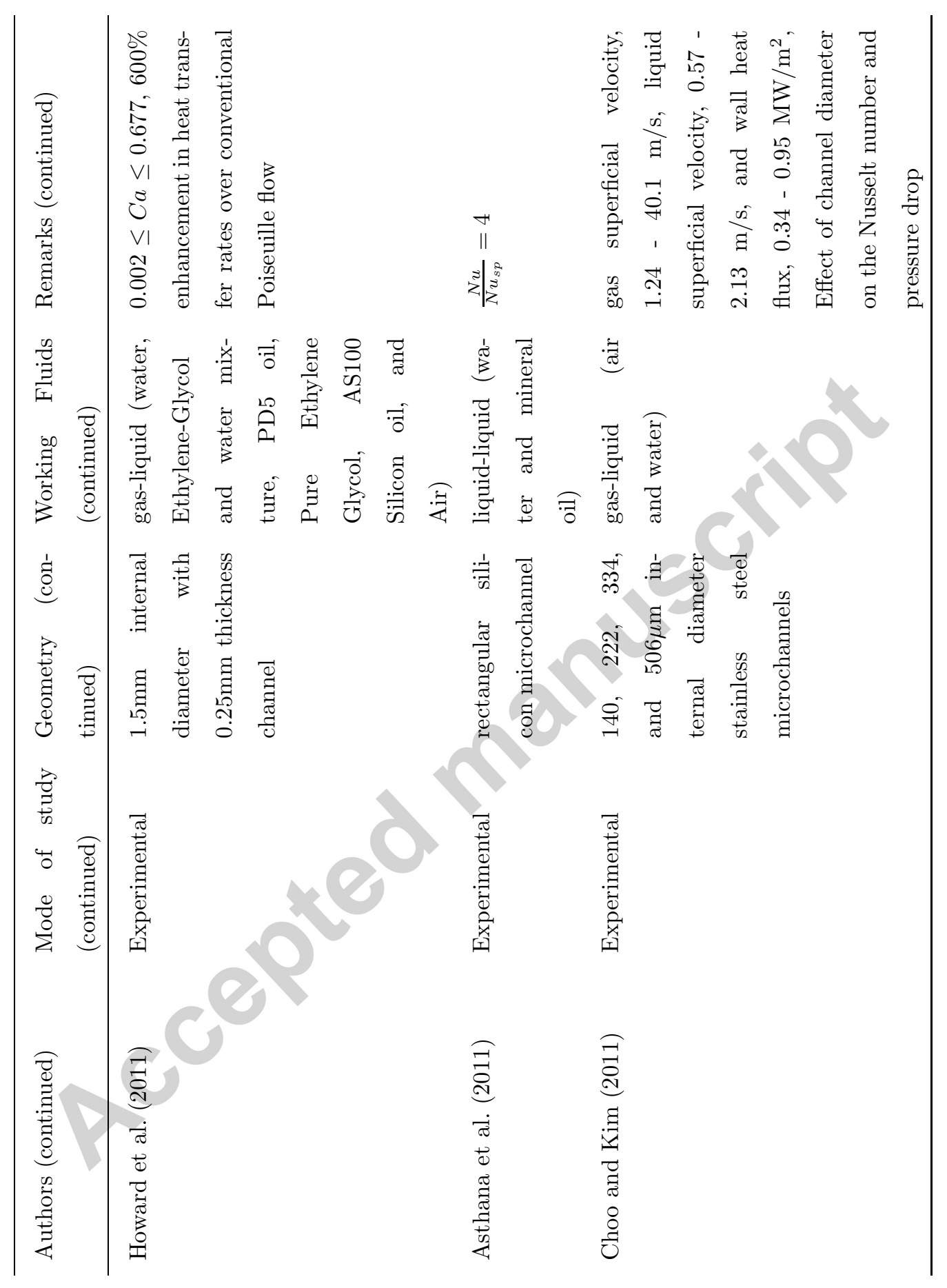




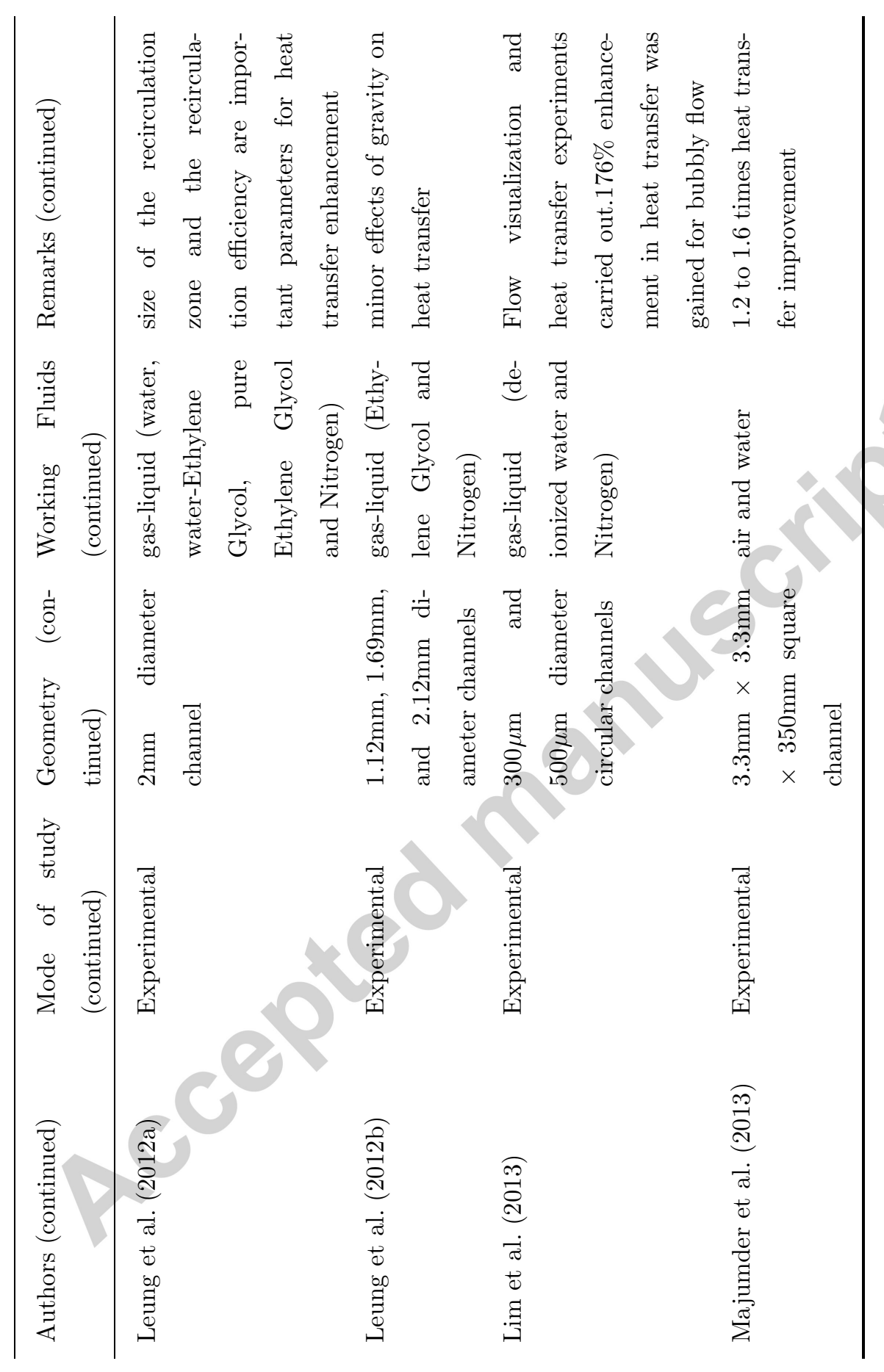




\section{Conclusion}

We have reviewed experimental and numerical studies on the hydrodynamics and heat transfer of slug flow in microchannels. Two-phase slug flow significantly increases heat flux relative to single phase flow with little consensus on the amount of enhancement. The studies revealed that using two immiscible liquids rather than gas-liquid gives further enhancement due to the higher heat capacity and thermal conductivity of liquids relative to gases. However, due to the larger viscosity of the liquids, the pump power of the system will be increased. Therefore, it is important to have a quantitative comparison between the energy consumption and the heat transfer enhancement in practical systems. Whilst the hydrodynamics of slug/Taylor flow are generally well understood there remain some gaps in the understanding of heat transfer process. Slug flow formation is an important stage in two-phase flow applications and proper techniques need to be studied experimentally in order to have controlled slug lengths and velocities.

The liquid film thickness in two-phase flow has been studied using both experimental and numerical methods. However, there are difficulties in capturing the liquid film thickness in numerical simulations due to the need for high grid resolution near the wall which is computationally costly. Therefore, it is necessary to develop modeling techniques that can capture the liquid film thickness that affects heat transfer, mass transfer, and pressure drop in microchannels. There are no significant experimental or numerical studies on liquid film thickness measurement in liquid-liquid two-phase flow and thus there are opportunities to develop that area.

We have highlighted a flow regime that has had little attention. At low 
$\mathrm{Ca}$ the slug can slide along the channel wall without a liquid film and thus the shape and the heat transfer depends on the contact angle.

Even though comprehensive studies have been conducted in the literature on two-phase flow pressure drop in microchannels, most of these experimental and numerical works are on gas-liquid two-phase flow with very little on liquid-liquid two-phase flow. Thus the analysis of pressure drop in liquidliquid two-phase flow will have significant interest among researchers and correlations are needed in designing microfluidic systems.

There are discrepancies of over $500 \%$ between $N u$ correlation results, even though a number of theoretical models have been developed to explain the relationship between the heat transfer and hydrodynamic parameters. New theoretical models are required to explain the relationship between heat transfer and parameters such as film thickness, pressure drop, void fraction, and contact angle etc in order to help resolve these discrepancies.

\subsection{Prospectives}

Beyond the fundamental aspects of traditional liquid-liquid Taylor flow systems being understudied, there are many opportunities to incorporate a range of convergent technologies and systems to take heat transfer enhancement to the next level. These include:

- Detailed studies on the impact of thermal conductivities of the two phases including systems with liquid metal for example.

- Heat transfer with Taylor flow in non-straight or uniform microchannels. The slugs can be manipulated using flow through various geometries such as diffuser/nozzle shapes, and curved and meandering 
channels. The asymmetry and chaotic advection within the slug can improve mass and heat transfer significantly.

- Solid/liquid/liquid system. Solid particles dispersed in at least one of the liquid phases has the potential to improve the heat transfer rate. Nanofluids with higher bulk thermal conductivity would increase the heat transfer rate. However dispersed nano/microparticles will affect the interfacial phenomena (including wetting, film thickness, liquid/liquid interfacial tension), so there is much work to be done in understanding their overall effect on heat transfer.

- Complex fluids and surfaces. A ferrofluid, for example, could be used for the slug and possibly the interface shape and the internal recirculating flow could be altered autonomously by the use of an external magnetic field. Similarly for the sliding slug condition, external methods such as electro-wetting could be used to control the contact line dynamics and slug interface shape and thus the heat transfer.

\section{Acknowledgement}

Australian Federal Government is thanked for their financial support through Australian Postgraduate Award (APA) for this study.

Abadie, T., Aubin, J., Legendre, D., Xuereb, C., 2012. Hydrodynamics of gas-liquid taylor flow in rectangular microchannels. Microfluidics and Nanofluidics 12 (1-4), 355-369.

Angeli, P., Gavriilidis, A., 2008. Hydrodynamics of taylor flow in small chan- 
nels: A review. Proceedings of the Institution of Mechanical Engineers, Part C: Journal of Mechanical Engineering Science 222 (5), 737-751.

Armand, A., Treschev, G., 1946. The resistance during the movement of a two-phase system in horizontal pipes. Izv. Vsev. Teplotak Tnst. 1, 16-23.

Asthana, A., Zinovik, I., Weinmueller, C., Poulikakos, D., 2011. Significant nusselt number increase in microchannels with a segmented flow of two immiscible liquids: An experimental study. International Journal of Heat and Mass Transfer 54 (7-8), 1456-1464.

Aussillous, P., Quere, D., 2000. Quick deposition of a fluid on the wall of a tube. Physics of Fluids 12 (10), 2367-2371.

Bahrami, M., Michael Yovanovich, M., Richard Culham, J., 2007. A novel solution for pressure drop in singly connected microchannels of arbitrary cross-section. International Journal of Heat and Mass Transfer 50 (13-14), 2492-2502, cited By (since 1996) 33.

Bandara, T., Chueng, S., Rosengarten, G., 2014. Numerical study of slug flow heat transfer in microchannels. In: Proc. of International Heat Transfer Conference 15. Begell House Inc.

Bao, Z., Fletcher, D., Haynes, B., 2000. An experimental study of gas-liquid flow in a narrow conduit. International Journal of Heat and Mass Transfer 43 (13), 2313-2324.

Bao, Z.-Y., Bosnich, M., Haynes, B., 1994. Estimation of void fraction and pressure drop for two-phase flow in fine passages. Chemical Engineering Research and Design 72 (A5), 625-632. 
Bar-Cohen, A., Arik, M., Ohadi, M., 2006. Direct liquid cooling of high flux micro and nano electronic components. Proceedings of the IEEE 94 (8), $1549-1570$.

Betz, A., Attinger, D., 2010. Can segmented flow enhance heat transfer in microchannel heat sinks? International Journal of Heat and Mass Transfer 53 (19-20), 3683-3691.

Bhagwat, S., Ghajar, A., 2014. A flow pattern independent drift flux model based void fraction correlation for a wide range of gas-liquid two phase flow. International Journal of Multiphase Flow 59, 186-205.

Bretherton, F. P., 1961. The motion of long bubbles in tubes. Journal of Fluid Mechanics 10 (02), 166-188.

Carlomagno, G. M., Cardone, G., 2010. Infrared thermography for convective heat transfer measurements. Experiments in fluids 49 (6), 1187-1218.

Ceccio, S., George, D., 1996. A review of electrical impedance techniques for the measurement of multiphase flows. Journal of Fluids Engineering, Transactions of the ASME 118 (2), 391-399.

Che, Z., Wong, T., Nguyen, N.-T., 2011. An analytical model for plug flow in microcapillaries with circular cross section. International Journal of Heat and Fluid Flow 32 (5), 1005-1013.

Che, Z., Wong, T., Nguyen, N.-T., 2012. Heat transfer enhancement by recirculating flow within liquid plugs in microchannels. International Journal of Heat and Mass Transfer 55 (7-8), 1947-1956. 
Che, Z., Wong, T., Nguyen, N.-T., 2013. Heat transfer in plug flow in cylindrical microcapillaries with constant surface heat flux. International Journal of Thermal Sciences 64, 204-212.

Choo, K., Kim, S., 2011. Heat transfer and fluid flow characteristics of nonboiling two-phase flow in microchannels. Journal of Heat Transfer 133 (10).

de Ryck, A., 2002. The effect of weak inertia on the emptying of a tube. Physics of Fluids 14 (7), 2102-2108.

Di Miceli Raimondi, N., Prat, L., Gourdon, C., Cognet, P., 2008. Direct numerical simulations of mass transfer in square microchannels for liquidliquid slug flow. Chemical Engineering Science 63 (22), 5522-5530.

Dreyfus, R., Tabeling, P., Willaime, H., 2003. Ordered and disordered patterns in two-phase flows in microchannels. Physical Review Letters 90 (14), $144505 / 1-144505 / 4$.

Eain, M., Egan, V., Punch, J., Walsh, P., Walsh, E., 2013. An investigation of the pressure drop associated with liquid-liquid slug flows. In: ASME 2013 11th International Conference on Nanochannels, Microchannels and Minichannels, ICNMM 2013.

Ebadian, M., Lin, C., 2011. A review of high-heat-flux heat removal technologies. Journal of Heat Transfer 133 (11), 110801(11 pages).

Fairbrother, F., Stubbs, A., 1935. Studies on electro-endosmosis. part vi. the "bubble-tube" method of measurement. Journal of the Chemistry Society $1,527-529$. 
Fischer, M., Juric, D., Poulikakos, D., 2010. Large convective heat transfer enhancement in microchannels with a train of coflowing immiscible or colloidal droplets. Journal of Heat Transfer 132 (11), 112402 (10 pages).

Foroughi, H., Kawaji, M., 2010. Immiscible liquid-liquid two-phase flow in a microchannel: Flow patterns and pressure drop characteristics. 7th Inetrantional Conference on Multiphase Flow, 1-5.

Foroughi, H., Kawaji, M., 2011. Viscous oil-water flows in a microchannel initially saturated with oil: flow patterns and pressure drop characteristics. International Journal of Multiphase Flow 37 (9), 1147-1155.

Fukagata, K., Kasagi, N., Ua-arayaporn, P., Himeno, T., 2007. Numerical simulation of gas-liquid two-phase flow and convective heat transfer in a micro tube. International Journal of Heat and Fluid Flow 28 (1 SPEC. ISS.), 72-82.

Godbole, P., Tang, C., Ghajar, A., 2011. Comparison of void fraction correlations for different flow patterns in upward vertical two-phase flow. Heat Transfer Engineering 32 (10), 843-860.

Grad, M., Tsai, C., Yu, M., Kwong, D.-L., Wong, C., Attinger, D., 2010. Transient sensing of liquid films in microfluidic channels with optofluidic microresonators. Measurement Science and Technology 21 (7), 075204 (8 pages).

Gupta, R., Fletcher, D., Haynes, B., 2010a. Cfd modelling of flow and heat transfer in the taylor flow regime. Chemical Engineering Science 65 (6), 2094-2107. 
Gupta, R., Fletcher, D., Haynes, B., 2010b. Taylor flow in microchannels: A review of experimental and computational work. Journal of Computational Multiphase Flows 2 (1), 1-31.

Han, Y., Shikazono, N., 2009a. Measurement of liquid film thickness in micro square channel. International Journal of Multiphase Flow 35 (10), 896-903.

Han, Y., Shikazono, N., 2009b. Measurement of the liquid film thickness in micro tube slug flow. International Journal of Heat and Fluid Flow 30 (5), 842-853.

Hazuku, T., Fukamachi, N., Takamasa, T., Hibiki, T., Ishii, M., 2005. Measurement of liquid film in microchannels using a laser focus displacement meter. Experiments in Fluids 38 (6), 780-788.

He, Q., Hasegawa, Y., Kasagi, N., 2010. Heat transfer modelling of gas-liquid slug flow without phase change in a micro tube. International Journal of Heat and Fluid Flow 31 (1), 126-136.

Heil, M., 2001. Finite reynolds number effects in the bretherton problem. Physics of Fluids 13 (9), 2517-2521.

Hetsroni, G., Mosyak, A., Pogrebnyak, E., Segal, Z., 2009. Heat transfer of gas-liquid mixture in micro-channel heat sink. International Journal of Heat and Mass Transfer 52 (17-18), 3963-3971.

Hoang, A., Berteloot, G., Sharif-Kashani, P., Kavehpour, H., 2012. Dynamic measurement of microfilms and nanofilms of fluids using fluorescence microscopy. Experiments in Fluids 52 (6), 1657-1662. 
Howard, J., Walsh, P., 2013. Review and extensions to film thickness and relative bubble drift velocity prediction methods in laminar taylor or slug flows. International Journal of Multiphase Flow 55, 32-42.

Howard, J., Walsh, P., Walsh, E., 2011. Prandtl and capillary effects on heat transfer performance within laminar liquid-gas slug flows. International Journal of Heat and Mass Transfer 54 (21-22), 4752-4761.

Hughmark, G., 1965. Holdup and heat transfer in horizontal slug gas-liquid flow. Chemical Engineering Science 20 (12), 1007-1010.

Irandoust, S., Andersson, B., 1989. Liquid film in taylor flow through a capillary. Industrial and Engineering Chemistry Research 28 (11), 1684-1688.

Jovanovic, J., Zhou, W., Rebrov, E., Nijhuis, T., Hessel, V., Schouten, J., 2011. Liquid-liquid slug flow: Hydrodynamics and pressure drop. Chemical Engineering Science 66 (1), 42-54.

Kariyasaki, A., Fukano, T., Ousaka, A., Kagawa, M., 1991. Characteristics of time-varying void fraction in isothermal air-water cocurrent flow in a horizontal capillary tube. Nippon Kikai Gakkai Ronbunshu, B Hen/Transactions of the Japan Society of Mechanical Engineers, Part B 57 (544), 4036-4043.

Kashid, M., Agar, D., 2007. Hydrodynamics of liquid-liquid slug flow capillary microreactor: Flow regimes, slug size and pressure drop. Chemical Engineering Journal 131 (1-3), 1-13.

Kashid, M., Gerlach, I., Goetz, S., Franzke, J., Acker, J., Platte, F., Agar, 
D., Turek, S., 2005. Internal circulation within the liquid slugs of a liquidliquid slug-flow capillary microreactor. Industrial and Engineering Chemistry Research 44 (14), 5003-5010.

Kawahara, A., Chung, P.-Y., Kawaji, M., 2002. Investigation of two-phase flow pattern, void fraction and pressure drop in a microchannel. International Journal of Multiphase Flow 28 (9), 1411-1435.

Kreutzer, M., Du, P., Heiszwolf, J., Kapteijn, F., Moulijn, J., 2001. Mass transfer characteristics of three-phase monolith reactors. Chemical Engineering Science 56 (21-22), 6015-6023.

Kreutzer, M., Kapteijn, F., Moulijn, J., Heiszwolf, J., 2005a. Multiphase monolith reactors: Chemical reaction engineering of segmented flow in microchannels. Chemical Engineering Science 60 (22), 5895-5916.

Kreutzer, M., Kapteijn, F., Moulijn, J., Kleijn, C., Heiszwolf, J., $2005 b$. Inertial and interfacial effects on pressure drop of taylor flow in capillaries. AIChE Journal 51 (9), 2428-2440.

Lakehal, D., Larrignon, G., Narayanan, C., 2008. Computational heat transfer and two-phase flow topology in miniature tubes. Microfluidics and Nanofluidics 4 (4), 261-271.

Leung, S., Gupta, R., Fletcher, D., Haynes, B., 2012a. Effect of flow characteristics on taylor flow heat transfer. Industrial and Engineering Chemistry Research 51 (4), 2010-2020.

Leung, S., Gupta, R., Fletcher, D., Haynes, B., 2012b. Gravitational effect 
on taylor flow in horizontal microchannels. Chemical Engineering Science 69 (1), 553-564.

Leung, S., Liu, Y., Fletcher, D., Haynes, B., 2010. Heat transfer in wellcharacterised taylor flow. Chemical Engineering Science 65 (24), 63796388.

Lim, Y., Yu, S., Nguyen, N., 2013. Flow visualization and heat transfer characteristics of gasliquid two-phase flow in microtube under constant heat flux at wall. International Journal of Heat and Mass Transfer 56 (12), $350-359$.

Liu, H., Vandu, C., Krishna, R., 2005. Hydrodynamics of taylor flow in vertical capillaries: Flow regimes, bubble rise velocity, liquid slug length, and pressure drop. Industrial and Engineering Chemistry Research 44 (14), 4884-4897.

Lockhart, R., Martinelli, R., 1949. Proposed correlations of data for isothermal two-phase two-component flow in pipes. Chemical Engineering Progress 45, 39-48.

Mac Giolla Eain, M., Egan, V., Punch, J., 2013. Film thickness measurements in liquid-liquid slug flow regimes. International Journal of Heat and Fluid Flow 44, 515-523.

Majumder, A., Mehta, B., Khandekar, S., 2013. Local nusselt number enhancement during gas-liquid taylor bubble flow in a square mini-channel: An experimental study. International Journal of Thermal Sciences 66, 818. 
Mehta, B., Khandekar, S., 2014. Measurement of local heat transfer coefficient during gas-liquid taylor bubble train flow by infra-red thermography. International Journal of Heat and Fluid Flow 45 (41-52), 41-52.

Mishima, K., Hibiki, T., 1996. Some characteristics of air-water two-phase flow in small diameter vertical tubes. International Journal of Multiphase Flow 22 (4), 703-712.

Mudawar, I., Bowers, M. B., 1999. Ultra-high critical heat flux (chf) for subcooled water flow boiling i: Chf data and parametric effects for small diameter tubes. International Journal of Heat and Mass Transfer 42 (8), $1405-1428$.

Muzychka, Y., Walsh, E., Walsh, P., 2011a. Heat transfer enhancement using laminar gas-liquid segmented plug flows. Journal of Heat Transfer 133 (4), 041902 (9 pages).

Muzychka, Y., Walsh, E., Walsh, P., Egan, V., 2011b. Nonboiling two-phase flow in microchannels. In: Microfluidics, Handbook, N. (Eds.), Sushanta K. Mitra, Suman Chakraborty. CRC Press.

Oliver, D., Wright, S., 1964. Pressure drop and heat transfer in gas-liquid slug flow in horizontal tubes. British Chemical Engineering 9, 590-596.

Oliver, D., Young Hoon, A., 1968. Two-phase non-newtonian flow ii heat transfer. Transaction of the Institution of Chemical Engineers 46, 116122.

Premoli, A., Fransesco, D., Prina, A., 1970. An empirical correlation for 
evaluating two phase mixture density under adaibatic conditions. European two-phase flow group meeting, Milan.

Prothero, J., Burton, A., 1961. The physics of blood flow in capillaries. i. the nature of the motion. Biophysical journal 1, 565-579.

Ratulowski, J., Chang, H.-C., 1990. Marangoni effects of trace impurities on the motion of long gas bubbles in capillaries. Journal of Fluid Mechanics 210, 303-328.

Rosenfeld, L., Lin, T., Derda, R., Tang, S., 2014. Review and analysis of performance metrics of droplet microfluidics systems. Microfluidics and Nanofluidics, 1-19.

Rosengarten, G., Harvie, D., Cooper-White, J., 2006. Contact angle effects on microdroplet deformation using cfd. Applied Mathematical Modelling 30 (10), 1033-1042.

Rosengarten, G., Tetuko, A., Li, K. K., Wu, A., Lamb, R., 2011. The effect of nano-structured surfaces on droplet impingement heat transfer. In: Proceedings of the ASME 2011 International Mechanical Engineering Congress and Exposition, IMECE2011. pp. 62835-1.

Salim, A., Fourar, M., Pironon, J., Sausse, J., 2008. Oil-water two-phase flow in microchannels: Flow patterns and pressure drop measurements. Canadian Journal of Chemical Engineering 86 (6), 978-988.

Santos, R., Kawaji, M., 2010. Effects of contact angle on gas slug formation, shape and flow in a microchannel t-junction by numerical simulations. In: International congress of Chemical and Process Engineering. 
Serizawa, A., Feng, Z., Kawara, Z., 2002. Two-phase flow in microchannels. Experimental Thermal and Fluid Science 26 (6-7), 703-714.

Shao, N., 2010. Gas-liquid two-phase flow and reaction in microstructured reactors. Ph.D. thesis, Department of Chemical Engineering, University college of London.

Shirtcliffe, N., McHale, G., Atherton, S., Newton, M., 2010. An introduction to superhydrophobicity. Advances in Colloid and Interface Science 161 (12), 124-138.

Suo, M., Griffith, P., 1964. Two phase in capillary tubes. Journal of Basic Engineering 86, 576-582.

Takamasa, T., Kobayashi, K., 2000. Measuring interfacial waves on film flowing down tube inner wall using laser focus displacement meter. International Journal of Multiphase Flow 26 (9), 1493-1507.

Talimi, V., Muzychka, Y., Kocabiyik, S., 2012. A review on numerical studies of slug flow hydrodynamics and heat transfer in microtubes and microchannels. International Journal of Multiphase Flow 39, 88-104.

Taylor, G. I., 1960. Deposition of a viscous fluid on a plane surface. Journal of Fluid Mechanics 9 (02), 218-224.

Taylor, G. I., 1961. Deposition of a viscous fluid on the wall of a tube. Journal of Fluid Mechanics 10, 161-165.

Triplett, K., Ghiaasiaan, S., Abdel-Khalik, S., LeMouel, A., McCord, B., 1999. Gas-liquid two-phase flow in microchannels part ii: Void fraction 
and pressure drop. International Journal of Multiphase Flow 25 (3), 395410.

Tsochatzidis, N., Karapantsios, T., Kostoglou, M., Karabelas, A., 1992. A conductance probe for measuring liquid fraction in pipes and packed beds. International Journal of Multiphase Flow 18 (5), 653-667.

Tuckerman, D., Pease, R., 1981. High-performance heat sinking for vlsi. Electron device letters EDL-2 (5), 126-129.

Urbrant, P., Leshansky, A., Halupovich, Y., 2008. On the force convective heat transport in droplet-laden flow in microchannels. Microfluidics Nanofluidicics 4, 533-542.

van Baten, J., Krishna, R., 2004. Cfd simulations of mass transfer from taylor bubbles rising in circular capillaries. Chemical Engineering Science 59 (12), $2535-2545$.

Walsh, E., Muzychka, Y., Walsh, P., Egan, V., Punch, J., 2009. Pressure drop in two phase slug/bubble flows in mini scale capillaries. International Journal of Multiphase Flow 35 (10), 879-884.

Walsh, P., Walsh, E., Muzychka, Y., 2010. Heat transfer model for gas-liquid slug flows under constant flux. International Journal of Heat and Mass Transfer 53 (15-16), 3193-3201.

Warnier, M., Rebrov, E., de Croon, M., Hessel, V., Schouten, J., 2007. Gas hold-up and liquid film thickness in taylor flow in rectangular microchannels. Chemical Engineering Journal 135 (SUPPL. 1), S153-S158. 
Woldesemayat, M., Ghajar, A., 2007. Comparison of void fraction correlations for different flow patterns in horizontal and upward inclined pipes. International Journal of Multiphase Flow 33 (4), 347-370.

Zhao, C.-X., 2013. Multiphase flow microfluidics for the production of single or multiple emulsions for drug delivery. Advanced Drug Delivery Reviews 65 (11-12), 1420-1446. 